\title{
The synthetic and therapeutic expedition of isoxazole and its analogs
}

\author{
Neetu Agrawal ${ }^{1} \cdot$ Pradeep Mishra $^{1}$
}

Received: 22 November 2017 / Accepted: 1 February 2018 / Published online: 27 February 2018

(c) Springer Science+Business Media, LLC, part of Springer Nature 2018

\begin{abstract}
Isoxazole, constituting an important family of five-membered heterocycles with one oxygen atom and one nitrogen atom at adjacent positions is of immense importance because of its wide spectrum of biological activities and therapeutic potential. It is, therefore, of prime importance that the development of new synthetic strategies and designing of new isoxazole derivatives should be based on the most recent knowledge emerging from the latest research. This review is an endeavor to highlight the progress in the chemistry and biological activity of isoxazole derivatives which could provide a low-height flying bird's eye view of isoxazole derivatives to the medicinal chemists for the development of clinically viable drugs using this information.
\end{abstract}

Keywords Heterocyclic $\cdot$ Isoxazole $\cdot$ Biological activity $\cdot$ Anticancer $\cdot$ Anti-inflammatory $\cdot$ Antimicrobial

\begin{tabular}{|c|c|c|c|}
\hline Abbreviations & & DPP & Dipeptidyl peptidse \\
\hline 5-HT & 5-hydroxy tryptamine & DPPH & 2,2-diphenyl-1-picrylhydrazyl \\
\hline A. clavatus & Aspergillus clavatus & E. coli & Escherichia coli \\
\hline A. fumigates & Aspergillus fumigatus & E. faecalis & Enterococcus faecalis \\
\hline A. niger & Aspergillus niger & E. floccosum & Epidermophyton floccosum \\
\hline AChE & Acetylcholinesterase & $\mathrm{EC}$ & Effective concentration \\
\hline AR & Adrenergic receptor & ED & Effective dose \\
\hline B. cinerea & Botrytis cinerea & ELISA & Enzyme-linked immunosorbent assay \\
\hline B. subtilis & Bacillus subtilis & EPAC & Exchange proteins directly activated by \\
\hline BBB & Blood-brain barrier & & cAMP \\
\hline C. albicans & Candida albicans & FLAP & 5-lipoxygenase-activating protein \\
\hline C. elegans & Caenorhabditis elegans & FLT & FMS-like tyrosine kinase \\
\hline C. neoformans & Cryptococcus neoformans & FRAP & Ferric-ion reducing antioxidant power \\
\hline C. tropicum & Chrysosporium tropicum & FXR & Farnesoid X receptor \\
\hline $\mathrm{CA}$ & Carbonic anhydrase & GABA & $\gamma$-amino butyric acid \\
\hline CDK & Cyclin-dependent kinase & HDAC & Histone deacetylase \\
\hline $\mathrm{CK}$ & Casein kinase & HDL & High density lipoprotein \\
\hline CNS & Central nervous system & HIV & Human immunodeficiency virus \\
\hline $\mathrm{COX}$ & Cyclooxygenase & HMEC & Human microvascular endothelial cells \\
\hline cyt & Cytochrome & Hsp & Heat shock protein \\
\hline D. myceliophagus & Ditylenchus myceliophagus & HSV & Herpes simplex virus \\
\hline DGAT & Diacylglycerol acyl transferase & HTS & High-throughput screening \\
\hline & & IC & Inhibitory concentration \\
\hline & & JNK & c-Jun N-terminal kinase \\
\hline & & K. pneumonia & Klebsiella pneumoniae \\
\hline$\triangle$ Neetu Agrawal & & L. donovani & Leishmania donovani \\
\hline kumkumagr.1990 & @gmail.com & LDL & Low density lipoprotein \\
\hline 1 Institute of Pharm & aceutical Research, GLA Uni & LPA & Lysophosphatidic acid \\
\hline Mathura, U.P., Inc & & mAChR & muscarinic acetylcholine receptor \\
\hline
\end{tabular}




$\begin{array}{ll}\text { MAO } & \text { Monoamine oxidase } \\ \text { MAP } & \text { Mitogen-activated protein } \\ \text { MBEC } & \text { Mouse brain endothelial cells } \\ \text { MES } & \text { Maximal electric shock } \\ \text { MIC } & \text { Minimum inhibitory concentration } \\ \text { MTB } & \text { Mycobacterium tuberculosis } \\ \text { MTT } & \text { 3-(4,5-dimethythiazol-2-yl)-2,5-diphenyl } \\ & \text { tetrazolium bromide } \\ \text { nAChR } & \text { nicotinic acetylcholine receptor } \\ \text { P. aeruginosa } & \text { Pseudomonas aeruginosa } \\ \text { P. chrysogenum } & \text { Penicillium chrysogenum } \\ \text { PPAR } & \text { Peroxisome proliferator-activated } \\ & \text { receptors } \\ \text { PTP } & \text { Protein tyrosine phosphate } \\ \text { R. cerealis } & \text { Rhizoctonia cerealis } \\ \text { R. oryzae } & \text { Rhizopus oryzae } \\ \text { S. aureus } & \text { Staphylococcus aureus } \\ \text { S. pyogenes } & \text { Streptococcus pyogenes } \\ \text { S. typhi } & \text { Salmonella typhi } \\ \text { S. typhimurium } & \text { Salmonella typhimurium } \\ \text { S1P } & \text { Sphingosine-1-phosphate } \\ \text { SAR } & \text { Structure-activity relationship } \\ \text { scPTZ } & \text { subcutaneous pentylenetetrazole } \\ \text { SIRT } & \text { Silent information regulators } \\ \text { sPLA } & \text { Secretory phospholipase A } \\ \text { STAT } & \text { Signal transducer and activator of } \\ & \text { transcription } \\ \text { T. mentagrophytes } & \text { Trichophyton mentagrophytes } \\ \text { T. rubrum } & \text { Trichophyton rubrum } \\ \text { TRPM } & \text { Transient receptor potential melastatin } \\ \text { TRPV } & \text { Transient receptor potential vanilloid } \\ & \end{array}$

\section{Introduction}

Heterocyclic compounds have attracted considerable attention as they act as a bridge between chemical and life sciences. A significant amount of contemporary investigation is currently pursued on these compounds worldwide. The chemistry of isoxazoles (Fig. 1) has been an interesting field of study for decades because of their prominent potential as analgesic (Karthikeyan et al. 2009), anti-inflammatory (Rajanarendar et al. 2015; Banoglu et al. 2016), anticancer (Kumbhare et al. 2012; Tzanetou et al. 2014), antimicrobial (Siddiqui et al. 2013; Basha et al. 2015), antiviral (Lee et al. 2009), anticonvulsant (Frølund et al. 2007), antidepressant ( $\mathrm{Yu}$ et al. 2012; Zhang et al. 2016) and immunosuppressant (Ye et al. 2015). The literature survey revealed that the substitution of various groups on the isoxazole ring imparts different activity.

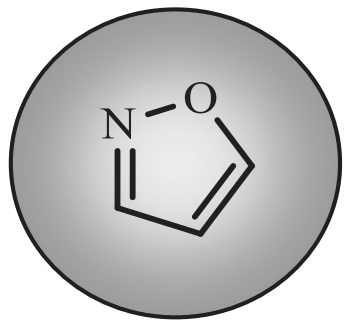

Fig. 1 Structure of isoxazole

Several marketed drugs with isoxazole nucleus belong to different categories with diverse therapeutic activities that have resulted in the development of a plethora of method for the synthesis of this valuable fragment. Such drugs are listed in Table 1. Inspired by these observations, this review summarizes current propensity in the isoxazole synthetic chemistry and divulges the utility of this potent nucleus as a rich source of new compounds having promising biological activities. Although several reviews have been published earlier on isoxazole (Manna et al. 2014; Hu and Szostak 2015; Chikkula and Raja 2017; Sysak and ObmińskaMrukowicz 2017), the focus was either synthetic routes or chemical reactions of the nucleus or the several biological activities of the isoxazole derivatives. Our effort is an exhaustive and systematic compilation of synthetic, as well as therapeutic voyage of isoxazole and its derivatives till now.

\section{Synthetic methods}

Literature survey revealed that several substituted isoxazoles had been prepared from numerous synthetic routes. The first contribution to the chemistry of isoxazoles was made by Claisen in 1903, when he synthesized the first compound of series, isoxazole, by oximation of propargylaldehyde acetal (Claisen 1903).

A regioselective, experimentally convenient one-pot copper(I)-catalyzed procedure was developed for the rapid synthesis of 3,5-disubstituted isoxazoles (Route a, Fig. 2) by reacting in situ generated nitrile oxides and terminal acetylenes (Hansen et al. 2005). Reddy et al. synthesized 3,5-disubstituted isoxazoles (Route b, Fig. 2) using $p$ tosylalcohol(TSA)-catalyzed reaction between propargylic alcohols and N-protected hydroxylamines followed by tetrabutylammonium fluoride (TBAF) mediated detosylation 5-endo-dig cyclization (Raji Reddy et al. 2012). Perez et al. reported an experimentally and environmentally benign one-pot three component process for the regioselective synthesis of 3,5-disubstituted isoxazoles (Route c, Fig. 2) from aldehydes and alkynes using choline chloride $(\mathrm{ChCl})$ : urea as a biorenewable deep eutectic solvent (DES). DES are an environmentally benign alternative to hazardous 
Table 1 Marketed drugs containing isoxazole nucleus

\begin{tabular}{lll}
\hline S. No. & Name of the drug & Structure \\
\hline 1 & Sulfamethoxazole &
\end{tabular}

2

Sulfisoxazole

3

\section{Acetyl sulfisoxazole}

\section{Cycloserine}

Acivicin

5

6

Broxaterol

7

\section{Oxacillin}

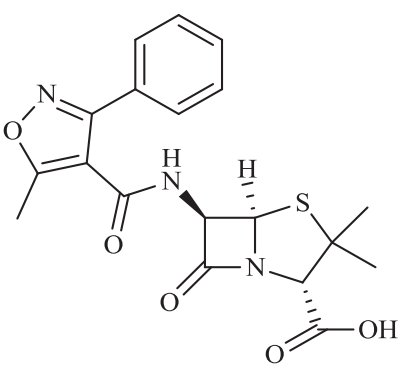

Pharmacological class

Antibacterial (Majewsky et al. 2014)

Antibacterial (Genc et al. 2008)<smiles>Cc1noc(NS(=O)(=O)c2ccc(N)cc2)c1C</smiles><smiles>CC(=O)N(c1onc(C)c1C)S(=O)(=O)c1ccc(N)cc1</smiles>

Antitubercular, Antileprotic (Desjardins et al. 2016)

Antitumour, Antileishmania (Conti et al. 2003)

Bronchodilatory agent (Giustina et al. 1995)

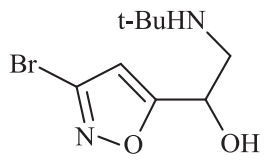

Antibacterial (Lainson et al. 2017) 
Table 1 (continued)

S. No. Name of the drug Structure

9

Isoxaflutole<smiles>COS(=O)(=O)c1cc(C(F)(F)F)ccc1C(=O)c1cnoc1C1CC1</smiles>

10

Zonisamide

11

Risperidone<smiles>Cc1nc2n(c(=O)c1CCN1CCC(c3noc4cc(F)ccc34)CC1)CCCC2</smiles>

Valdecoxib<smiles>Cc1onc(-c2ccccc2)c1-c1ccc(S(N)(=O)=O)cc1</smiles>

13

Danazol

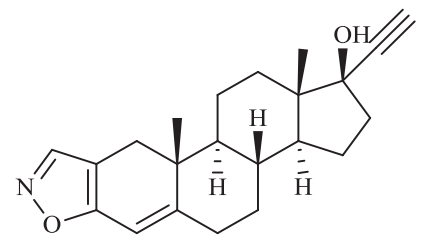

Pharmacological class

Antibacterial (Mani and Iyyadurai 2017)

Pesticide (Zhao et al. 2017a)

Anticonvulsant (Buoli et al. 2017), Antiobesity (Shin et al. 2014)

Antpsychotic

(Schoretsanitis et al. 2017)

COX-2 inhibitor (Bartzatt 2014)

Androgenic (McKinney et al. 2013) 
Table 1 (continued)

\begin{tabular}{|c|c|c|c|}
\hline S. No. & Name of the drug & Structure & Pharmacological class \\
\hline 14 & Leflunomide & & $\begin{array}{l}\text { Antirheumatic (Golicki } \\
\text { et al. 2012) }\end{array}$ \\
\hline 15 & Isocarboxazid & & $\begin{array}{l}\text { Antidepressant (Shader and } \\
\text { Greenblatt 1999) }\end{array}$ \\
\hline 16 & Drazoxolon & & $\begin{array}{l}\text { Antifungal (Lehtonen et al. } \\
\text { 1972) }\end{array}$ \\
\hline
\end{tabular}

(organic) solvents that can be recycled (Pérez and Ramón 2015). Jadhav et al. synthesized highly pure 3,5-disubstituted isoxazoles (Route d, Fig. 2) by converting aldoximes to nitrile oxides in the presence of Hydroxy (tosyloxy) iodobenzene (HTIB) and then reacting them with alkynes. The reagent HTIB is stable and can be handled without special care (Jadhav et al. 2013).

A highly regioselective method for the one-pot preparation of 3,5-disubstituted isoxazoles (Route e, Fig. 2) involves the reaction of terminal alkynes with $n$-BuLi and then aldehydes followed by the treatment with molecular iodine and subsequently with hydroxylamine (Harigae et al. 2014). Huang et al. (2014) reported an environmentally benign procedure for the synthesis of 3-alkyl-5-aryl isoxazoles (Route f, Fig. 2) under ultrasound radiation without using any catalyst. This method has advantages of easier work-up, mild reaction condition, high yields and shorter reaction time. Trogu et al. (2012) discovered a faster and efficient method for preparation of 3,5-disubstituted isoxazoles (Route g, Fig. 2) by base catalyzed condensation reactions of nitroacetic esters with dipolarophiles in the presence of water instead of chloroform.

Mohammed and coworkers synthesized isoxazoles (Route h, Fig. 2) using 1,8-diazabicyclo[5.4.0]undec-7-ene (DBU) as a reagent which promotes the 1,3-dipolar addition of nitrile oxides with alkynes without the use of metal (Mohammed et al. 2015). Kesornpun et al. performed cycloaddition of nitrile oxides with alkynes in aqueous solutions under acidic conditions rather than under the conventional basic conditions (Kesornpun et al. 2016). 5arylisoxazole derivatives (Route i, Fig. 2) can be synthesized using an environmentally benign procedure via the reaction of 3-(dimethylamino)-1-arylprop-2-en-1-ones with hydroxylamine hydrochloride in the aqueous medium without using any catalyst (Dou et al. 2013). Valizadeh et al. introduced an environment-friendly synthesis for 3,5disubstituted isoxazoles (Route j, Fig. 2) using ionic liquids (IL). A typical reaction of $\beta$-diketone with hydroxylamine was carried out in the IL, butylmethylimidazolium salts ([BMIM]X) to form isoxazoles in excellent yields (Valizadeh et al. 2009). The IL was recovered and recycled successfully.

Various methods have been reported to prepare isoxazoles with a variety of substituents at 3, 4, and 5 positions. Denmark and Kallemeyn (2005) first synthesized isoxazolylsilanols by [3+2] cycloaddition reaction between alkynyldimethylsilyl ethers and aryl and alkyl nitrile oxides (Route a, Fig. 3). The cross-coupling reaction of these heterocyclic silanols with a variety of aryl iodides leads to the formation of a variety of 3,4,5-trisubstituted isoxazoles. 
Fig. 2 Routes for the synthesis of 3,5-disubstituted isoxazoles

Route a

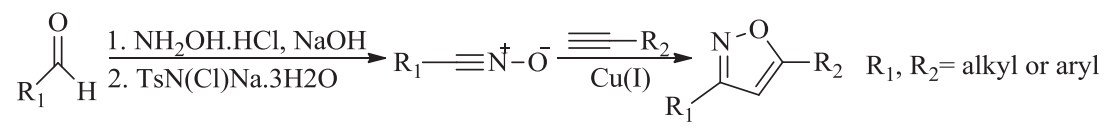

Route $\mathbf{b}$

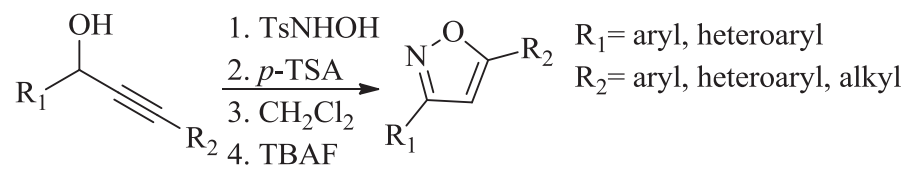

\section{Route c}

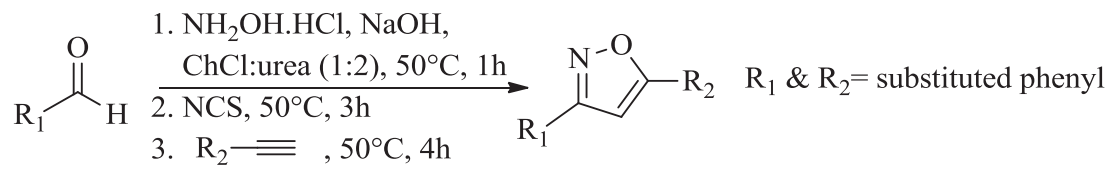

Route d

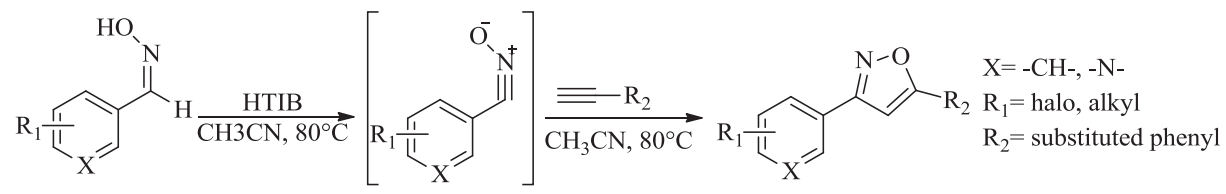

Route e

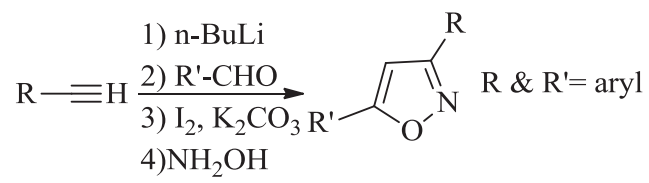

Route $\mathbf{f}$

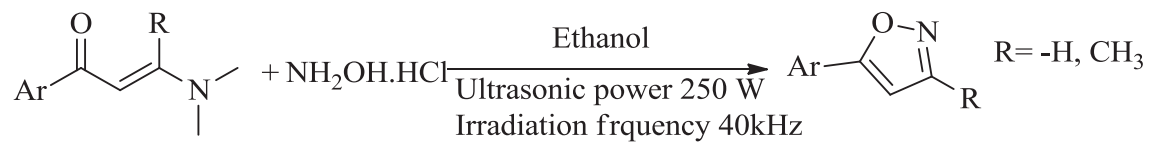

Route $\mathbf{g}$

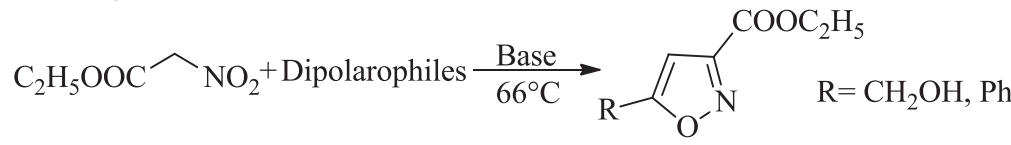

Route $\mathbf{h}$

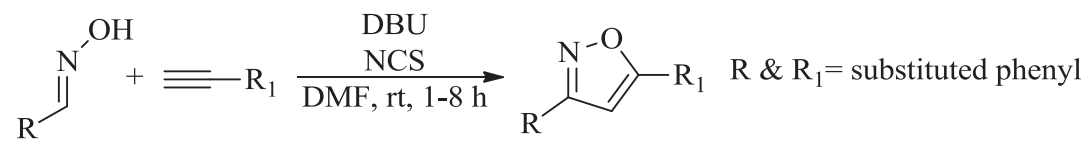

Route $\mathbf{i}$

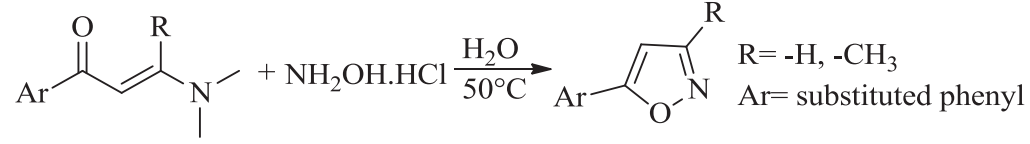

Route $\mathbf{j}$

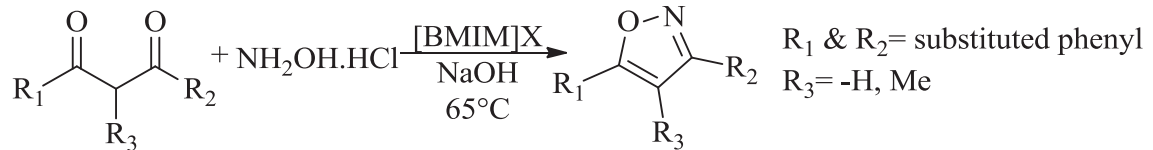

Gayon et al. (2011) synthesized trisubstituted isoxazoles using an uninterrupted four-step sequence method from readily available propargylic alcohols using sequentially iron and palladium catalyzed systems (Route b, Fig. 3).
The overall yields of this method were high, and it emerged as a time-saving procedure.

Recently, Li et al. (2017) used syringe pump infusion for the synthesis of polysubstituted isoxazoles (Route c, Fig. 3) 
Fig. 3 Routes for the synthesis of 3,4,5-trisubstituted isoxazoles

Route a
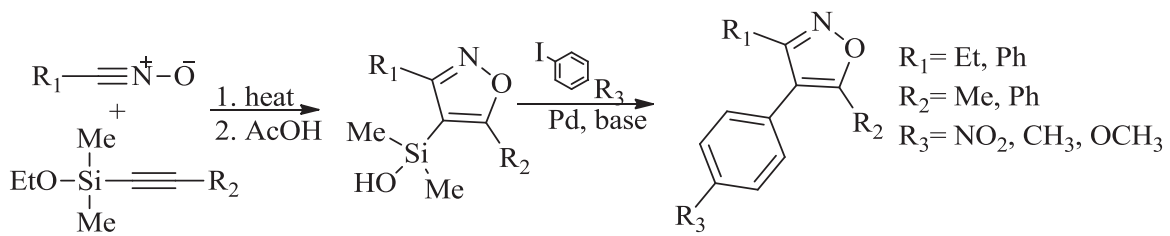

Route b

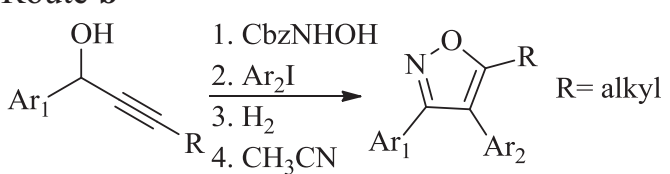

Route c

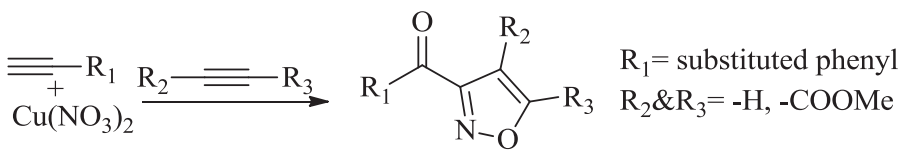

Route d

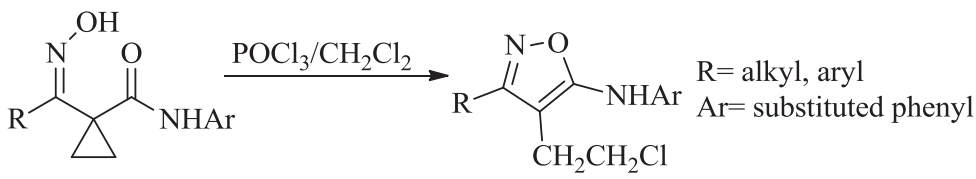

Route e

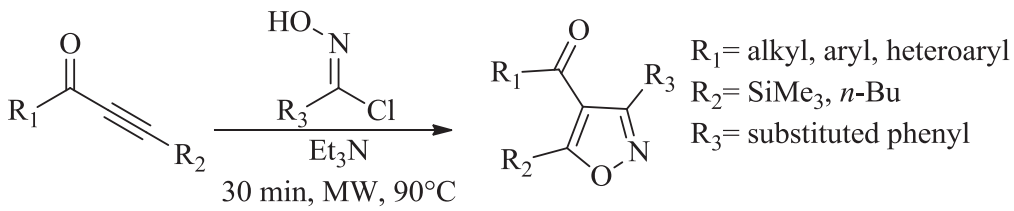

Route $\mathbf{f}$

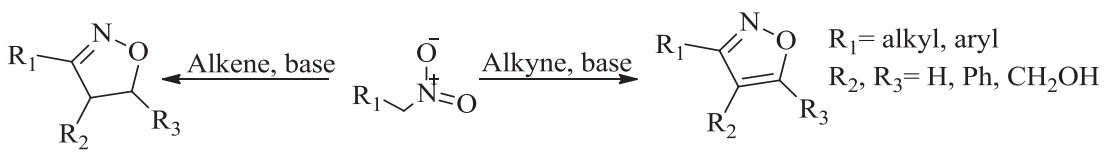

using a copper nitrate mediated synthesis from two different alkynes with high chemo-and regioselectivity. Substituted isoxazoles (Route d, Fig. 3) can be obtained from the cyclopropyl oximes (Wang et al. 2008) via ring-opening and intramolecular nucleophilic vinylic substitution reaction in the presence of $\mathrm{POCl}_{3} / \mathrm{CH}_{2} \mathrm{Cl}_{2}$. Willy et al. (2008) synthesized 3,4,5-substituted isoxazoles (Route e, Fig. 3) by cycloaddition reaction between in situ generated nitrile oxide and alkynones in the presence of triethylamine using dielectric heating for $30 \mathrm{~min}$. The primary activated nitro compounds condensed with alkenes to give isoxazolines and with alkynes to give isoxazoles (Route f, Fig. 3) in chloroform in the presence of 1,4-diazabicyclo[2.2.2]octane or other suitable $\mathrm{N}$-bases via 1,3-dipolar cycloaddition (Machetti et al. 2007).

Different methods have been reported for the synthesis of aminoisoxazoles. Treatment of $\beta$-ketonitriles with hydroxylamine in aqueous ethanol (Route a, Fig. 4) gives 3-aminoisoxazoles (Elnagdi et al. 1975). One-pot three- component coupling of $\beta$-oxo dithioesters, amines and hydroxylamine in ethanol at reflux affords 5-substituted 3-aminoisoxazoles (Route b, Fig. 4) via an in situ generated $\beta$-oxo thioamide intermediate (Samai et al. 2013). 4-aminoalkylisoxazol-3-ones can be obtained from 3-allyllactams (bielectrophiles) in high yields (Nenajdenko et al. 2005). During the course of the reaction, closure of one heterocycle is accompanied by the opening of the other (Route c, Fig. 4).

3-aminocrotononitrile reacts with hydroxylamine hydrochloride (Route d, Fig. 4) to give 5-amino-3methylisoxazole (Abushanab et al.. 1973). The $[2+3]$ cycloaddition reaction of nitrile oxides with captodative olefins or methyl crotonate derivatives is regioselective (Route e, Fig. 4) and leads to the formation of the 5substituted amino-isoxazole or the 4-substituted methoxycarbonyl-isoxazole derivatives, respectively (Lasri et al. 2008). The [4+1] cycloaddition reaction of isocyanides with $\alpha$-haloketone oxime (Route f, Fig. 4 ) in the presence of 
Fig. 4 Routes for the synthesis of aminoisoxazoles

\section{Route a}

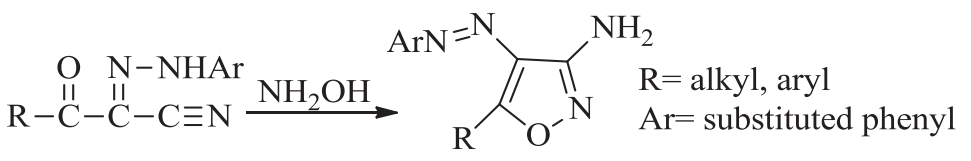

Route b

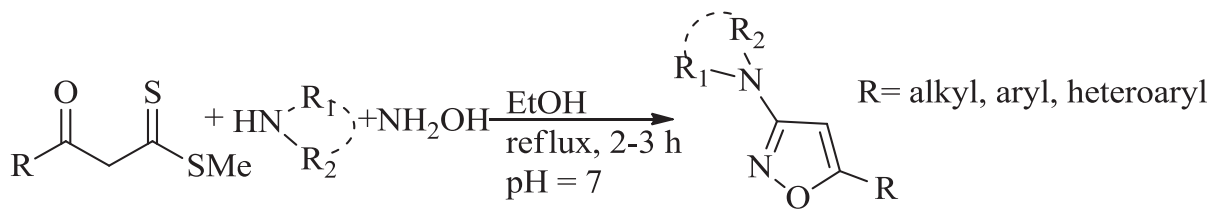

Route c

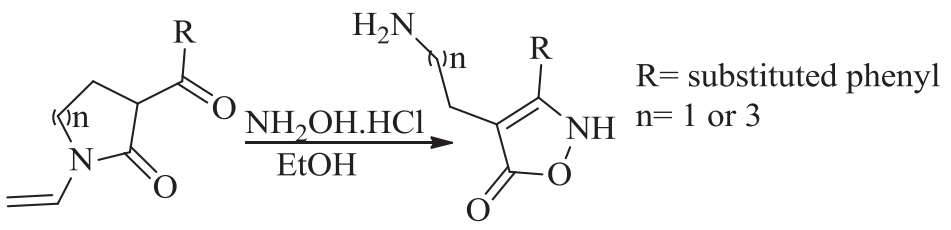

Route d

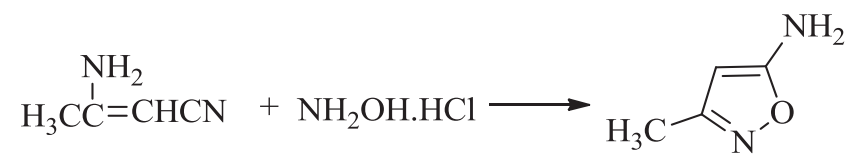

Route e

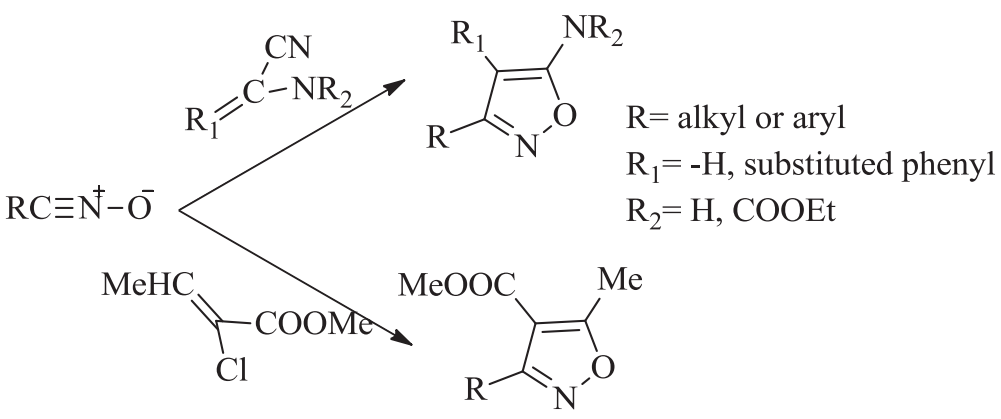

\section{Route $\mathbf{f}$}

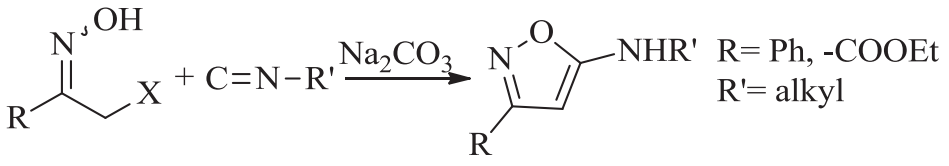

\section{Route $\mathbf{g}$}

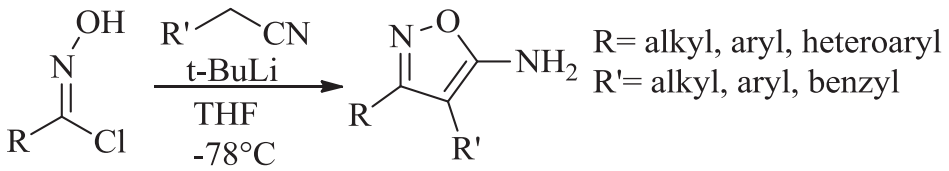

\section{Route h}

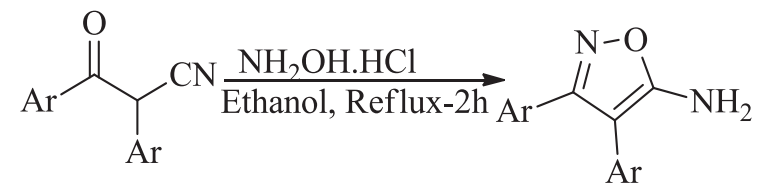

sodium carbonate yields 5-substituted aminoisoxazoles (Buron et al. 1997). While treatment of $\alpha$-chloro oximes with lithiated nitriles, produced a variety of 5-aminoisoxazoles (Route g, Fig. 4) with alkyl functionality at 4-position (Bourbeau and Rider 2006). Liu et al. (2009) prepared 5-aminoisoxazoles (Route h, Fig. 4) by 
Fig. 5 Routes for the synthesis of miscellaneous isoxazoles<smiles>[R][Z10]O[R]</smiles>

Route b<smiles>[R10][N+]1(Cc2conc2-c2ccccc2)C(C=O)C1c1ccccc1</smiles>

Route c

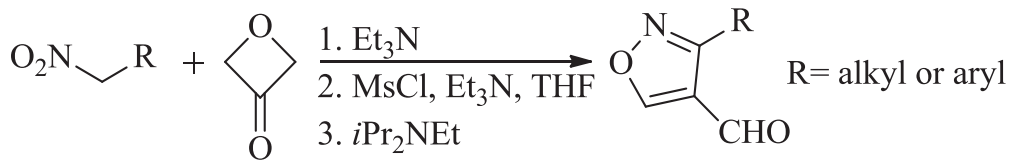

Route d

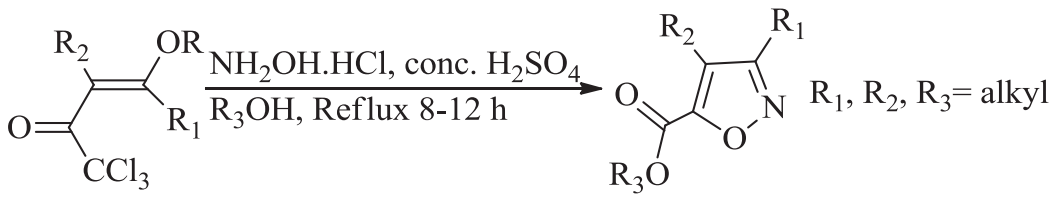

Route e

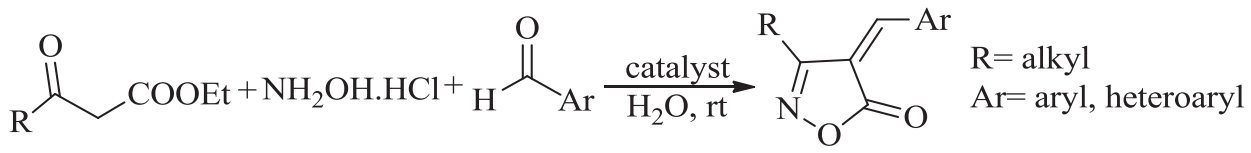

Route $\mathbf{f}$

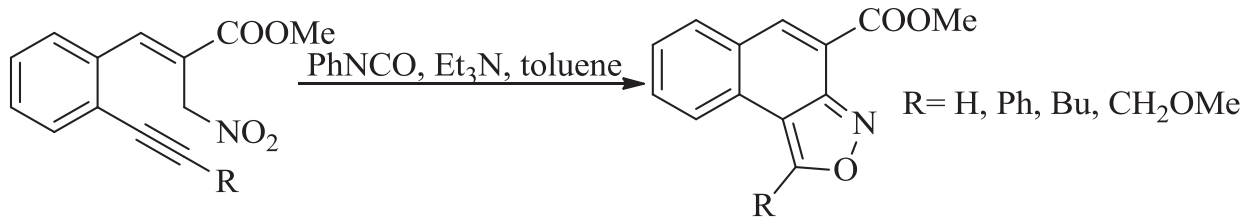

condensation of $\alpha$-cyanoketones with hydroxylamine hydrochloride in refluxing alcohol.

Aryl 1,3-diketoesters reacts hydroxylamine hydrochloride under different $\mathrm{pH}$ conditions. Acid conditions gave 3,5-isoxazole esters (Route a, Fig. 5) principally whereas reactions under neutral and basic conditions led to different 4,5 and 2,3-dihydro-hydroxy-isoxazoles, respectively (Andrzejak et al. 2010). Heating of 2-formyl azirines for $24 \mathrm{~h}$ in toluene at $200^{\circ} \mathrm{C}$ (Route b, Fig. 5) affords isoxazole (Brahma and Ray 2008). 3-substituted isoxazoles-4- carbaldehyde (Route c, Fig. 5) can be prepared by condensation reaction of nitroalkanes with 3-oxetanone (Burkhard et al. 2011). Martins et al. (2000) reported the synthesis of 5-carboxyisoxazoles (Route d, Fig. 5) from the cyclocondensation of $\beta$-alkoxyvinyl trichloromethyl ketones with hydroxylamine in a hydrochloric acid or sulphuric acid medium.

$4 H$-isoxazol-5-ones were synthesized by one-pot threecomponent condensation of aryl aldehydes, hydroxylamine hydrochloride and ketoesters using potassium phthalimide 
Fig. 6 Routes for the synthesis of miscellaneous isoxazoles
Route a<smiles>[R2]Cc1cc([R])no1</smiles>

Route $\mathbf{b}$

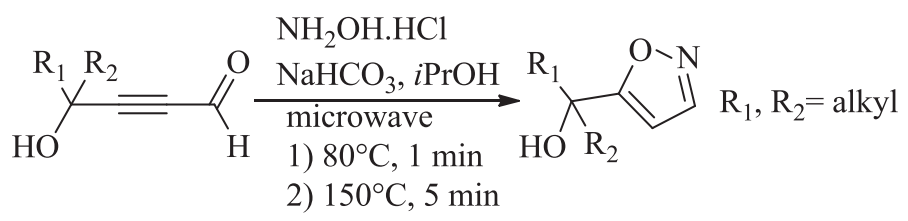

Route c

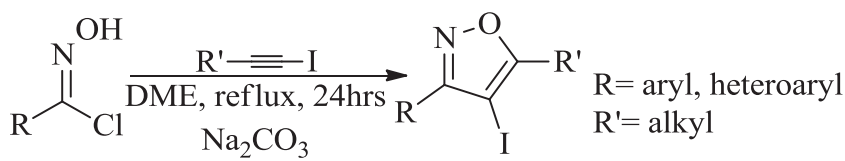

Route d

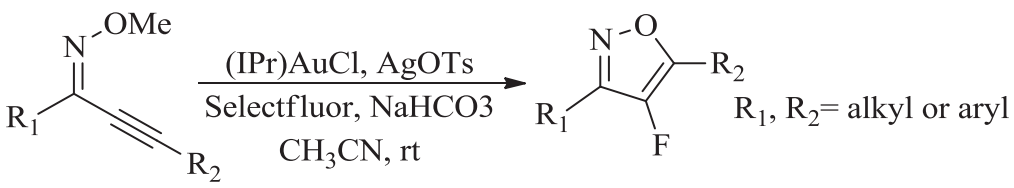

Route e

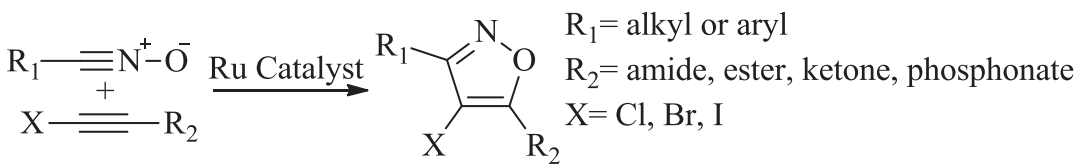

(Kiyani and Ghorbani 2013d), sodium ascorbate (Kiyani 2013), sodium tetraborate (Kiyani and Ghorbani 2013b), sodium azide (Kiyani and Ghorbani 2013c), sodium citrate (Kiyani and Ghorbani 2013a), sodium saccharin (Kiyani and Ghorbani 2013e), N-bromosuccinimide (Kiyani et al. 2015) or boric acid (Kiyani and Ghorbani 2015) as a catalyst in aqueous medium at room temperature (Route e, Fig. 5). Later Chavan et al. (2015) synthesized $4 H$-isoxazol-5ones efficiently by one-pot uncatalyzed reaction of hydroxylamine hydrochloride, ketoesters and aromatic aldehydes substituted with electron donating group in the aqueous medium. Ji et al. (2006) synthesized 4-carbomethoxynaphtho[2,1-c]isoxazoles (Route f, Fig. 5) from methyl 3(alkynylphenyl)-2-propenoates by the intramolecular nitrile oxide cycloaddition.

Allegretti and Ferreira (2013) reported cyclization of propargylic N-hydroxycarbamates and $\mathrm{N}$-alkoxycarbonyl amino ethers (Route a, Fig. 6) via Pt-carbene intermediate to differentially substituted regioisomeric isoxazoles. Recently, Bulanov et al. (2017) reported an efficient, catalyst-free and microwave assisted one pot method for synthesis of 5-substituted isoxazoles (Route b, Fig. 6) from $\alpha$-acetylenic $\gamma$-hydroxyaldehydes and hydroxylamine. Crossley and Browne (2010) synthesized a series of iodoisoxazoles (Route c, Fig. 6) by reacting hydroximinoyl chlorides and iodinated terminal alkynes. Jeong et al. (2014) synthesized a series of fluoroisoxazoles (Route d, Fig. 6) using one-pot gold-catalyzed tandem cyclization-fluorination of (Z)-2-alkynone O-methyl oxime under mild conditions (room temperature). Further, Oakdale et al. (2014) synthesized 4-haloisoxazoles (Route e, Fig. 6) using ruthenium-catalyzed cycloaddition of nitrile oxides with electronically deficient 1 -haloalkynes.

\section{Biological activities}

Owing to the diverse and potential pharmacological activities of the isoxazole ring, many researchers across the globe are engaged in the development of pharmacologically 
active agents bearing it. The following discussions illustrate the pharmacological applications of isoxazole against various biological properties.

\section{Analgesic and anti-inflammatory activity}

Rajanarendar et al. (2015) synthesized some 6-methyl isoxazolo[5,4- $d]$ isoxazol-3-yl aryl methanones, assessed them for molecular properties prediction, drug-likeness, lipophilicity and solubility parameters, evaluated for in vitro COX inhibitory activity and screened for anti-inflammatory activity using carrageenan induced paw edema method. The compounds with chloro or bromo substitutions on phenyl ring (1; Fig. 7) exhibited significant antiinflammatory activity and were more selective towards COX-2 enzyme. Habeeb et al. (2001) reported the synthesis of 4,5-diphenyl-4-isoxazolines possessing a variety of substituents at the para position of one of the phenyl ring and evaluated for analgesic and selective COX-2 antiinflammatory activity. The compounds having C-3 Me substituent on central isoxazoline ring were potent analgesics, as well as selective towards COX-2. 4,5-diphenyl-5-(4-methylsulfonylphenyl)-4-phenyl-4-isoxazoline and screened for anti-inflammatory activity. Among these, the compound 2 (Fig. 7) having a sulfonylmethyl group at the para position of phenyl ring was most potent analgesic, as well as anti-inflammatory agent. Molecular modeling studies on $\mathbf{2}$ showed that the $\mathrm{S}$ atom of sulfonylmethyl and the C-3 Me group was crucial for selective inhibition of COX-2. Perrone et al. (2016) synthesized a new series of isoxazole and evaluated them for their COX inhibitory activity and selectivity. Compound $\mathbf{3}$ (Fig. 7) was found to be a sub-micromolar selective COX-2 inhibitor $\left(\mathrm{IC}_{50}\right.$ $0.95 \mu \mathrm{M})$.

Some indolyl-isoxazoles (4; Fig. 7) were synthesized by Panda et al. and evaluated for acute anti-inflammatory activity using carrageenan-induced rat paw edema method. All the compounds exhibited good anti-inflammatory activity ranging from 36.6 to $73.7 \%$ reduction in edema (Panda et al. 2009). Another series of indole derivatives bearing isoxazoline moiety were synthesized by Amir et al. (2010) and tested in vivo for their anti-inflammatory activity by carrageenan-induced rat paw edema method. From these studies compound 5 (Fig. 7) showed maximum antiinflammatory activity along with a maximum reduction in ulcerogenic activity and lipid peroxidation. Karthikeyan et al. (2009) reported the synthesis of a series of pyrazolyl isoxazolines 6 and isoxazoles 7 (Fig. 7) using 1,3-dipolar cycloaddition of pyrazole derived nitrile oxides with various dipolarophiles. The synthesized compounds were evaluated for antinociceptive activity. All the compounds displayed efficacy comparable to standard drugs pentazocine and aspirin.
Chemical-cooling agents like menthol induce analgesia by activating TRPM 8 channels that act as a $\mathrm{Ca}^{2+}$-permeable ligand-gated cation channel. Some aminoisoxazole-based derivatives synthesized by Ostacolo et al. (2013) were able to modulate TRPM8 that can be used for cold-evoked analgesia. The ability of the compounds to act as TRPM8 agonists was studied using $\left[\mathrm{Ca}^{2+}\right]$-imaging experiments in sensory neurons in vitro, and an in vivo model of cold allodynia. Some of the compounds were up to 200 -fold more potent than menthol, but none of them showed improved efficacy. The compound 8 (Fig. 7) was most promising. TRPV1 channels are $\mathrm{Ca}^{2+}$-permeable nonselective cation channel expressed in primary afferent neurons and are the integrator of nociceptive responses to both chemical and noxious stimuli. After the HTS, Palin et al. (2011) synthesized an isoxazole-3-carboxamide series and evaluated them for their ability to modulate TRPV1 channel. Substitution of isoxazole-3-carboxamide with $1 S$, $3 R$-3-aminocyclohexanol motif (compounds 9 and 10; Fig. 7) aided both potency and solubility. These compounds were further progressed to animal studies, where both the compounds attenuated the acute inflammatory response in the rat complete Freund's adjuvant assay.

A series of 4,5-diaryloisoxazol-3-carboxylic acids was synthesized by Banoglu et al. (2016) as leukotriene biosynthesis inhibitors targeting FLAP. Leukotrienes have important roles in various inflammatory diseases. In the very first step of leukotriene biosynthesis, there is an involvement of FLAP. Compounds 11a and 11b (Fig. 7) emerged as potent anti-inflammatory agents possessing potent inhibitory activity against cellular 5-Lipoxygenase product synthesis with $\mathrm{IC}_{50}$ of $0.24 \mu \mathrm{M}$ each. Silva et al. (2002) synthesized isoxazole derivatives as nAChR ligands for the development of analgesics. nAChR has gained much attention due to beneficial effects of nicotine in CNS disorders such as Alzheimer's disease, Parkinson's disease, and pain reflexes. Compound 12 (Fig. 7) displayed the best analgesic profile in the series. Peifer et al. (2009) synthesized 3,4-diaryl isoxazoles as a dual inhibitor of p38 $\alpha$ MAP kinase and CK1 $\delta$. Compounds 13 and 14 (Fig. 7) were found to be highly potent dual inhibitors of $\mathrm{p} 38 \alpha$ and CK1 $1 \delta$. p38 $\alpha$ MAP kinase plays a major role in signal transduction of severe inflammatory diseases like rheumatoid arthritis, asthma and autoimmune disorders (Peifer et al. 2006). Laufer et al. (2006) synthesized 3,4 and 4,5-disubstituted and 3,4,5-trisubstituted isoxazoles which were tested in an in vitro ELISA of isolated p38 MAP kinase and for inhibitory potency against cytP450 to develop agents for the treatment of rheumatoid and inflammatory diseases. The pyridinyl isoxazole (15; Fig. 7) displayed significant suppression of cytokine release, low affinity towards cytP450 and potent inhibitory activity towards isolated p38 MAP kinase. 


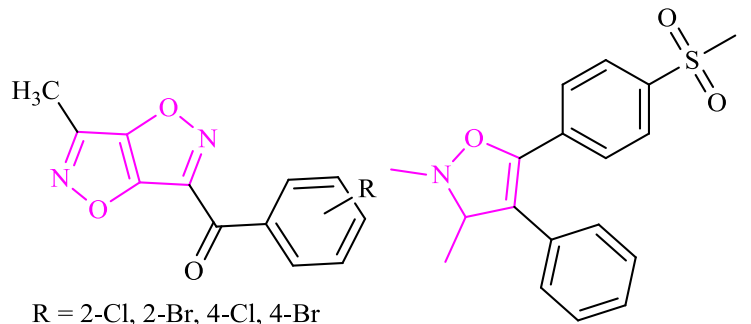

1<smiles>COc1ccc(-c2noc(CC(=O)N3CCc4cc(OC)c(OC)cc4C3)c2-c2ccc(OC)cc2)cc1</smiles>

3

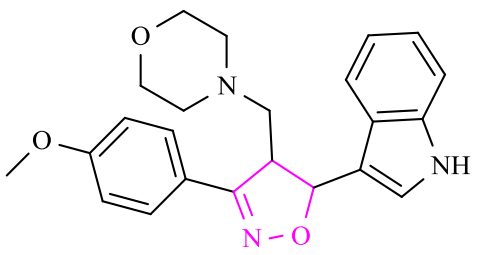

5<smiles>[R7]c1ccc(-c2nn(-c3ccccc3)cc2C2=NOC3C(=O)N([R1])C(=O)C23)cc1</smiles>

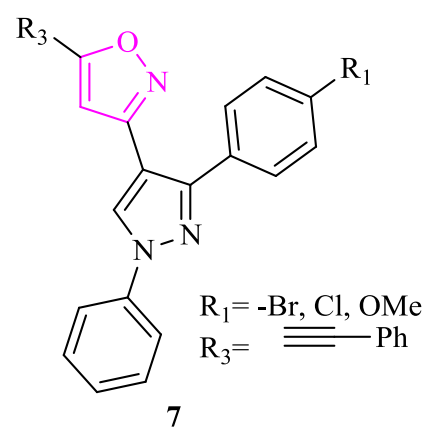<smiles>CCCCNc1cc(C)on1</smiles><smiles>[R]c1ccc(-c2onc(C(=O)N[C@@H]3CCC[C@@H](O)C3)c2Cl)cc1[R]</smiles>

$9 \mathrm{R}_{1}=\mathrm{CF}_{3}, \mathrm{R}_{2}=\mathrm{H}$

$10 R_{1} \& R_{2}=F$<smiles>[R]COc1ccc(-c2onc(C(=O)O)c2-c2ccc(Cl)cc2)cc1</smiles>

11<smiles></smiles><smiles>Cc1cc(-c2ccc(Cl)cc2Cl)on1</smiles><smiles>CC(C)c1onc(-c2ccc(F)cc2)c1-c1ccnc(N[C@H](C)c2ccccc2)c1</smiles>

13<smiles>CC(C)c1onc(-c2ccc(F)cc2)c1-c1ccnc(NC(=O)Cc2ccc(F)cc2)c1</smiles>

14<smiles>Fc1ccc(-c2nocc2-c2ccncc2)cc1</smiles>

15

Fig. 7 Isoxazole derivativess showing analgesic and anti-inflammatory activity (1-15) 
<smiles>Nc1onc(-c2ccc(Cl)o2)c1-c1ccccc1</smiles>

16<smiles>COc1ccc(-c2noc3c2CCc2cc(OC)c(OC)cc2-3)cc1OC</smiles>

18<smiles>Cc1ccn2cc(-c3ccc(NC(=O)Nc4cc(C(C)(C)C)on4)cc3)nc2c1</smiles>

19<smiles>Cc1ccc(NC(=O)c2cc(N3CCN(C)CC3)cc(C(F)(F)F)c2)cc1NC(=O)c1cnoc1C</smiles>

20<smiles>CCCc1cc2ccccc2nc1-c1cc(-c2ccc(C(F)(F)F)cc2)no1</smiles>

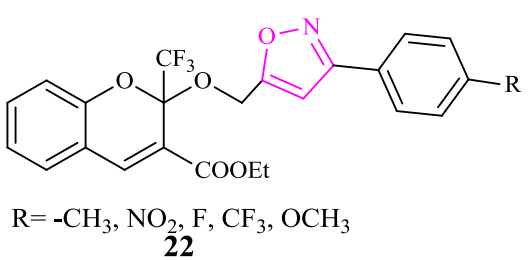

21<smiles>[R]c1ccccc1-c1cc(COc2ccc3oc(=O)ccc3c2)on1</smiles>

23<smiles>[R4]C=[R4]=C</smiles>
$25 \mathrm{R}=-\mathrm{CH}_{3}, \mathrm{R}^{\prime}=-\mathrm{H}$<smiles>[R]c1ccc(-c2cc(COc3ccccc3-c3nc4ccccc4s3)on2)cc1</smiles>

26<smiles>CC(C)c1cc(-c2noc(NC(=O)C3CC3)c2-c2ccc(CN3CCC(N4CCOCC4)CC3)cc2)c(O)cc1O</smiles>

28<smiles>COC(=O)[C@H](NC(=O)COCCOCCOCCNC(=O)c1noc(-c2cc(C(C)C)c(O)cc2O)c1-c1ccc(CN2CCOCC2)cc1)C(C)C</smiles>

Fig. 8 Isoxazole derivatives showing anticancer activity (16-29)

\section{Antitumor/anticancer activity}

Vitale et al. (2014) designed and synthesized new isoxazoles taking [3-(5-chlorofuran-2-yl)-5-methyl-4-phenylisoxazole], a highly selective COX-1 inhibitor (Vitale et al. 2013) as a lead. COX-1 inhibition is considered as a promising therapeutic strategy for cancer and neuro-inflammation-derived neurodegenerative diseases. All the compounds were evaluated for their in vitro COX inhibitory activity and selectivity. The substitution of methyl in the lead compound with an amino group (16; Fig. 8) improved the COX-1 selectivity and inhibitory activity. Instead low or no activity was observed for its $N, N$-dialkyl and $N, N$-diacetyl derivatives. The inhibitory activity of compound $\mathbf{1 6}$ (Fig. 8) was also assessed in ovarian cancer cell line (OVCAR-3) where it was found to be 20-fold more potent than the lead compound. 
Shaw et al. (2012) synthesized N-phenyl-5carboxamidyl isoxazoles and screened for their cytotoxic activity against colon 38 and CT-26 mouse colon tumor cells. The most active and solid-tumor compound $\mathbf{1 7}$ (Fig. 8) ( $\left.\mathrm{IC}_{50} 2.5 \mu \mathrm{g} / \mathrm{mL}\right)$ significantly downregulated the expression of phosphorylated-STAT3, a novel target for chemotherapeutic drugs, in both human and mouse colon cancer cells. Tzanetou et al. (2014) synthesized tetraloneisoxazole fused compounds and evaluated in four different cell lines: two endothelial cell lines (HMEC-1 and MBEC) and two tumor cell lines [human cervical carcinoma (HeLa) and human breast carcinoma (MCF-7) cells. Compound 18 (Fig. 8) exhibited promising cytostatic activity, demethylation of which led to 10 -fold less active compound.

Over-expression of FLT3 plays a critical role in development and progress of acute myeloid leukemia. Xu et al. (2015) designed and synthesized a series of novel N-(5(tert-butyl)isoxazol-3-yl)-N'-phenylurea derivatives as FLT 3 inhibitors. Among the synthesized compounds, compound 19 (Fig. 8) inhibited the phosphorylation of FLT3 and led to complete tumor regression in the MV4-11 xenograft model. Compound 19 (Fig. 8) also displayed acceptable aqueous solubility, desirable pharmacokinetic properties and high cytotoxic selectivity against MV4-11 cells. SAR studies revealed that an electron-rich fused ring (R) at the phenyl was beneficial for the antiproliferative activity. Im et al. (2015) synthesized a series of 4arylamido 3-methylisoxazoles and evaluated them for antiproliferative activities against the A375P melanoma and U937 hematopoietic cell lines. Most of the compounds displayed selective antiproliferative activity toward the U937 cell line, and the activities were better than the reference drug Sorafenib while weak cytotoxic activities against human normal cell line and A375P. The most potent inhibitor 20 (Fig. 8) was found to be a potent inhibitor of FMS kinase too with an $\mathrm{IC}_{50}$ of $9.95 \mathrm{nM}$. The FMS kinase inhibitors have great potential in the treatment of bone osteolysis and inflammation, as well as cancers promoted by macrophages.

Sambasiva Rao et al. (2014) synthesized 5-(3-alkylquinolin-2-yl)-3-aryl isoxazole derivatives and screened against four human cancer cell lines (A549, COLO 205, MDA-MB 231 and PC-3). Compound 21(Fig. 8) showed potent cytotoxicity against all the tested cell lines at $\mathrm{IC}_{50}<$ $12 \mu \mathrm{M}$. The SAR revealed that fluorine or trifluoromethyl group at the fourth position of phenyl in isoxazole ring promotes the cytotoxicity. Ratnakar Reddy et al. (2014) prepared isoxazole functionalized chromene derivatives (22; Fig. 8) and screened against four human cancer cell lines namely A549-Lung Cancer (CCL-185), MCF7-Breast cancer (HTB-22), DU145-Prostate cancer (HTB-81), HeLaCervical cancer (CCL-2) using 5-Fluorouracil as a positive control by MTT assay. All the compounds displayed poor to moderate activity.

Shakeel-u-Rehman et al. (2014) linked 6hydroxycoumarins to isoxazole and screened for their cytotoxic activity against five different human cancer cell lines namely prostate (PC-3), colon (HCT-116 and Colo205), leukemia (HL-60) and lung (A-549). The ortho substituted isoxazole derivatives of 6-hydroxy coumarin (23; Fig. 8) emerged as effective cytotoxic agents against PC-3 cancer cell line. Rajanarendar et al. (2015) synthesized a series of novel isoxazolo $\left[5^{\prime}, 4^{\prime}: 5,6\right]$ pyrido[2,3- $\left.b\right]$ indoles and evaluated against three human cancer cell lines Hela, MCF7 and NCI-H460 (lung cancer) according to MTT assay method using Cisplatin as a reference drug. Compounds $\mathbf{2 4}$ and 25 (Fig. 8) displayed potent anticancer activity comparable to reference drug towards all the tested cancer cell lines. Rest of the compounds exhibited moderate to good anticancer activity with low selectivity.

Isoxazoles linked 2-phenylbenzothiazole 26 (Fig. 8), synthesized by Kumbhare et al. (2012), displayed significant anticancer activity against MCF-7 cells ( IC $_{50} 26-43$ $\mu \mathrm{M}$ ), A549 cells (human lung adenocarcinoma; $\mathrm{IC}_{50}$ 11-24 $\mu \mathrm{M}$ ) and Colo-205 cells (human colon cancer; $\mathrm{IC}_{50}$ 11-21 $\mu \mathrm{M})$ and possessed the ability to cause apoptosis. Özkay et al. (2013) synthesized some isoxazole-(benz)azole derivatives and evaluated them for cytotoxic effects on HT-29 (colon carcinoma) and C-6 (melanoma) cell lines using MTT assay. The compounds which displayed significant cytotoxicity were selected and then analyzed for their inhibitory activity on DNA synthesis of carcinogenic cells. The compounds 27a and 27b (Fig. 8) showed potent cytotoxic activity against both cancer cell lines and displayed significant inhibitory activity on DNA synthesis of carcinogenic cells.

Hsp90 is overexpressed in a number of human cancers that makes it a potential target for cancer treatment. Chen et al. (2014) synthesized a series of small molecules with 4,5-diarylisoxazole scaffold and evaluated them for Hsp90 inhibitory activity. In this series, compound 28 (Fig. 8) showed high affinity for Hsp90 and strongly inhibited it at both molecular and cellular level. Further in vivo studies showed that compound $\mathbf{2 8}$ (Fig. 8) strongly suppresses the tumor growth of human glioblastoma xenograft model U87MG and displayed good results in pharmacokinetic and safety experiments. Another series of 4,5-diaryl isoxazoles was synthesized by Zhang et al. (2017) by incorporating diversified amino acid derivatives with various lengths to the 3-amido motif. These compounds were evaluated for Hsp90 inhibitory activity and antiproliferative activity against H3122 human lung cancer and BT-474 breast cancer cells. Compound 29 (Fig. 8) bearing a terminal valine methyl ester and an ethylene glycol-containing linear linker displayed high Hsp90 binding potency (14 nM), as well as 
<smiles>[R]C[Y9]1ccc(-c2noc3c2C(=O)c2c([R2])cccc2C3=O)cc1</smiles>

$\mathrm{R} 1=-\mathrm{Ph}, 2-\mathrm{Pyrazine}$ $\mathrm{R} 2=-\mathrm{H}, \mathrm{OH}, \mathrm{OAc}, \mathrm{OMe}$ 30<smiles>CCCCNC(=O)c1noc2c1CN(C(=O)Nc1cc(C(C)C)c(O)cc1O)CC2</smiles>

31<smiles>COc1cc(C2=NOC(c3cc(OC)c(OC)c(OC)c3)C2)ccc1OCCCOc1cc2c(cc1OC)C(=O)N1CCCC1C=N2</smiles><smiles>COc1ccc(-c2c(-c3cc(OC)c(OC)c(OC)c3)noc2N)cc1</smiles>

34<smiles>COc1ccc(-c2c(-c3cc(OC)c(OC)c(OC)c3)noc2N(C(C)=O)C(C)=O)cc1</smiles><smiles>COc1ccc(/C=C\c2cc(OC)c(OC)c(OC)c2)cc1O</smiles><smiles>Cn1cc(-c2cc(-c3cn(C)c4ccccc34)on2)c2ccccc21</smiles><smiles>CC1(C)CCC(C)(C)c2cc(-c3cc(-c4ccc(C(=O)O)cc4)no3)ccc21</smiles>

Fig. 9 Isoxazole derivatives showing anticancer activity (30-38)

antiproliferative activity against the tested cell lines. Bargiotti et al. (2012) synthesized isoxazolo(aza)naphthoquinones and evaluated them for cytotoxic Hsp90 inhibitory activity in a series of human tumor cell lines. Most of the compounds mainly 3-pyridyl derivatives (30; Fig. 9) displayed high affinity and potent antiproliferative activity.

Baruchello et al. (2014) reported Hsp90 and HDAC6 inhibitory activity of 4,5,6,7-tetrahydro-isoxazolo-[4,5-c] pyridine compounds and evaluated for antiproliferative activity. The N-5 substitution with a 2,4-resorcinol carboxamide appeared to be crucial for activity. Compound $\mathbf{3 1}$ (Fig. 9) with a long chain hydroxamic residue bound to C-3 amide portion inhibited both Hsp90 and HDAC6. Kamal et al. synthesized a series of 3,5-diaryl isoxazoline/isoxazole linked pyrrolo-benzodiazepine (Kamal et al. 2010) and 2,3dihydroquinazolinones (Kamal et al. 2011) and evaluated for their anticancer activity. From the former series, compound 32 (Fig. 9) exhibited G0/G1 arrest, activation of caspase-3 and finally apoptotic cell death. Compound $\mathbf{3 3}$ (Fig. 9) from the latter series showed the disruption of microtubules, as well as fragmentation of nuclei and emerged as an efficient cyclin B1 inhibitor, as well as a CDK1 inhibitor and this hybrid compound was effective against 18 human cancer cell lines. 
Liu et al. (2009) synthesized a series of cis-restricted 3,4diaryl-5-aminoisoxazoles and evaluated against five human cancer cell lines (human myeloid leukemia cells K562, human esophageal carcinoma cells ECA-109, human nonsmall lung cancer cells A549, human hepatocellular carcinoma cells SMMC-7721, and human prostate carcinoma cells PC-3). The tested compounds displayed more potent cytotoxic activity against leukemia cells K562 than other cell lines. However, the compounds 34 (Fig. 9) and its $N, N$ diacetyl derivative (35; Fig. 9) exhibited potent in vitro cytotoxic activities with $\mathrm{IC}_{50}$ values in the range of $0.04-12.00 \mu \mathrm{M}$ against all tested cancer lines and inhibited tubulin polymerization similar to that of combretastatin A-4 (36; Fig. 9), a potent antitumor agent.

Diana et al. (2010) synthesized a series of novel 2,5-bis (3'-indolyl)furans and 3,5-bis(3'-indolyl)isoxazoles and evaluated their antiproliferative activity in vitro against diverse human tumor cell lines. Among the isoxazoles, compound 37 (Fig. 9) was found to be most active and showed high selectivity towards 29 cell lines. Simoni et al. (2001) synthesized retinoic acid receptor ligands with potent apoptotic activity. Retinoids play a major role in regulating the growth and differentiation of a wide variety of normal and malignant cell types. Compound $\mathbf{3 8}$ (Fig. 9) exhibited good affinity for the retinoid receptors. Moreover, its ability to act on K562 and HL60R cell lines suggested its important implications in the treatment of different leukemias.

SIRT1/SIRT2 inhibitors have been found to possess antitumor activity. Mahajan et al. (2014) synthesized pyrazolone and isoxazol-5-one cambinol analogs and reported their sirtuin inhibitory activity with in vitro and in vivo antilymphoma activity. Among them, the isoxazole derivatives have emerged as selective SIRT 2 inhibitor displaying $>15.4-$ fold SIRT-2 selectivity. The SIRT-2 selective inhibitor 39 (Fig. 10) exhibited potent cytotoxicity in both lymphoma and epithelial cancer cell lines with $\mathrm{IC}_{50}$ ranging from 3 to $7 \mu \mathrm{M}$.

Panathur et al. (2015) synthesized a new series of indole-isoxazolone hybrids bearing substituted amide, substituted [(1,2,3-triazol-4-yl)methoxy]methyl group or substituted benzylic ether at position- 2 of the indole. The molecules were screened for anticancer activity against three human cancer cell lines (MDA-MB-231, MCF-7, and HT-29). Most of the trifluoromethyl substituted derivatives exhibited better growth inhibition activity than their methyl substituted analogs. The SIRT1 inhibition activity of two potent molecules (40a and 40b; Fig. 10) was investigated, and the SIRT1 $\mathrm{IC}_{50}$ values were 35.25 and $37.36 \mu \mathrm{M}$, respectively. 3-amino-benzo[ $[d]$ isoxazole based compounds were synthesized by Jiang et al. (2015) and evaluated for their tyrosine kinase c-Met inhibitory activity. This tyrosine kinase c-Met is a receptor for hepatocyte growth factor. Abnormality in this pathway leads to tumor growth, angiogenesis, and metastasis. Compound 41a and 41b
(Fig. 10) displayed most potent c-Met inhibitory activity both at enzymatic $\left(\mathrm{IC}_{50} 1.8 \mathrm{nM}\right)$ and cellular $\left(\mathrm{IC}_{50} 0.18 \mathrm{nM}\right)$ levels with high antiproliferative efficacy against EBC-1 (human lung squamous carcinoma) cell line.

Chouaiib et al. (2016) synthesized 3,5-disubstituted isoxazoles from natural maslinic acid and oleanolic acids and evaluated them for anti-inflammatory and antiproliferative activity against murine mammary carcinoma cell line EMT6 and human colorectal adenocarcinoma cell line SW480. Among all the derivatives, the compound 42 (Fig. 10) bearing a furfuryl ring at its isoxazole moiety was found to possess promoting anti-inflammatory and anticancer effects. Najafi et al. (2015) prepared triazole-isoxazole derivative and evaluated for their cytotoxic activity against two human breast cancer cell lines MCF-7 and T-47D. Compounds 43a and 43b (Fig. 10) were found to be effective in vitro anticancer agents. However, no compound showed significant activity against tested cancer cell lines.

Pedada et al. (2016) synthesized a series of indolecontaining isoxazoles and evaluated them for $\mathrm{SPLA}_{2}$ inhibitory activity. $\mathrm{SLA}_{2}$ inhibitors are used for the preventive and therapeutic treatment of inflammatory diseases including cancer. All the compounds showed significant in vitro and in vivo $\mathrm{SPA}_{2}$ inhibitory activity. It was observed that isoxazoles with an electron withdrawing group like-F, $\mathrm{CF}_{3}$ on phenyl ring displayed excellent $\mathrm{sPLA}_{2}$ inhibitory activities. In particular, compound $\mathbf{4 4}$ (Fig. 10) showed potent $\mathrm{sPLA}_{2}$ inhibitory activity comparable to positive control ursolic acid and exhibited in vitro antiproliferative activity against MCF-7 breast and DU145 prostate cancer cell lines. Yang et al. (2017) synthesized pyridinyl-4,5-2H-isoxazole derivatives and evaluated them for their in vitro inhibitory activity against MCF-7 cell line. Only the compounds with hydrophobic groups on phenyl displayed potent biological activities. Compounds 45a and 45b (Fig. 10) displayed highest anti-tumor activity and were found to possess potent antiproliferative activity against Human hepatoma cell line (HepG2) and cervical cancer cell line (HeLa) also.

Kalirajan et al. (2012) synthesized isoxazole substituted 9-anilinoacridine derivatives and evaluated them for in vitro antioxidant, as well as cytotoxic activity against Hep2 cell line. All the compounds possessed significant antioxidant activity and compound 46 (Fig. 10) displayed potent anticancer activity. Md Tohid et al. (2012) synthesized diarylisoxazoles containing an indole group either at 3position or 5-position of isoxazole core and evaluated for their pro-apoptotic antitumor activity. The indol-5-yl substituted compounds (47; Fig. 10) were the most active, as well as selective when tested for their in vitro growth inhibitory activity against Colo320 (colon) and Calu-3 (lung) human cancer cell lines. These compounds had little or no effect on normal cell line viability suggesting their selective pro-apoptotic antitumor effects. 
<smiles>[R]C1=NOC(=O)/C1=C/c1c(COCc2ccc(C(F)(F)F)cc2)n(C)c2ccc(F)cc12</smiles><smiles>[R]Oc1cc(C(=O)NCc2cn(Cc3ccc([R])cc3)nn2)no1</smiles><smiles>Cc1ccc2[nH]cc(CNCc3cc(-c4ccc(F)c(C(F)(F)F)c4)no3)c2c1</smiles><smiles>[R]Nc1ncc(C)c(NCC2CC(c3cc(NC(=O)c4cc(C(F)(F)F)cc(C(F)(F)F)c4)cnc3C)=NO2)n1</smiles><smiles>O=[N+]([O-])c1cccc(-c2cc(-c3ccc(Nc4c5ccccc5nc5ccccc45)cc3)no2)c1</smiles><smiles>[R][R]([R]#[R])OC</smiles>

47

Fig. 10 Isoxazole derivatives showing anticancer activity (39-47)

\section{Antimicrobial activity}

RamaRao et al. (2011) synthesized 5-(heteroaryl)isoxazoles and evaluated for antibacterial activity against $E$. coli, $S$. aureus and $P$. aeruginosa. The isoxazoles substituted with 2thienyl (48; Fig. 11) or 5-bromo-2-thienyl moieties (49; Fig. 11 ) in the 5-position displayed significant activity. Gautam and Singh (2013) synthesized a series of 4,5-dihydro-5(substitutedphenyl)-3-(thiophene-2-yl)isoxazole and were tested in vitro for their antibacterial activity against $S$. aureus, B. subtilis, E.coli and P. aeruginosa and their antifungal activity against $A$. niger and $C$. albicans using disc diffusion method. The compound $\mathbf{5 0}$ (Fig. 11) was found to be highly active against E.coli, $P$. aeruginosa and $C$. albicans which may be attributed to its increased lipid solubility due to the presence of chloride on the aromatic ring. The rest of the compounds were found to be moderate to highly active. Basha et al. (2015) synthesized some thiazolyl isoxazoles and studied their antibacterial activity against $S$. aureus, B. subtilis, $K$. pneumoniae and $P$. aeruginosa and their antifungal activity against $A$. niger and $P$. chrysogenum. Thiazolyl isoxazoles having phenyl ring (51; Fig. 11) substituted with chloro and nitro were found to be potential antibacterial agents against $S$. aureus and A. niger.

In (1,4-phenylene)bis(arylsulfonyl isoxazoles) series synthesized by Lavanya et al. (2014), the compound substituted with chloro on the aromatic ring (52; Fig. 11) exhibited excellent antibacterial activity $(38 \mathrm{~mm}$ at $100 \mu \mathrm{g} / \mathrm{mL}$ ) against $B$. subtilis, while rest of the compounds inhibited the spore germination against $P$. chrysogenum and 
<smiles>[R]c1ccc(-c2cc(-c3sc(Cl)nc3Cl)on2)cc1</smiles><smiles></smiles><smiles>[R]c1cccc(C2C3C(=O)N([R])C(=O)C3ON2C)c1</smiles>

$\mathrm{R}=p-\mathrm{NEt}_{2}, p-\mathrm{NMe}_{2}, p-\mathrm{Me}, p-\mathrm{Cl}, m-\mathrm{Cl}, m-\mathrm{Br}$ $\mathrm{R}^{\prime}=\mathrm{Me}, \mathrm{Ph}$

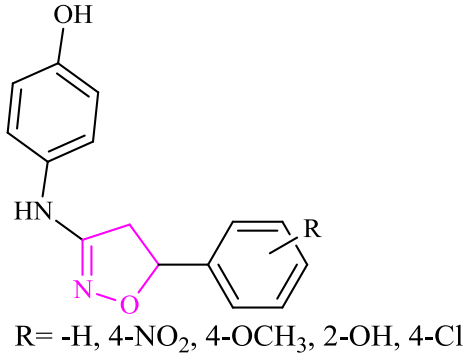

55<smiles>Brc1ccc(Cn2c(Cc3noc4ccccc34)nc3ccccc32)cc1</smiles>

56

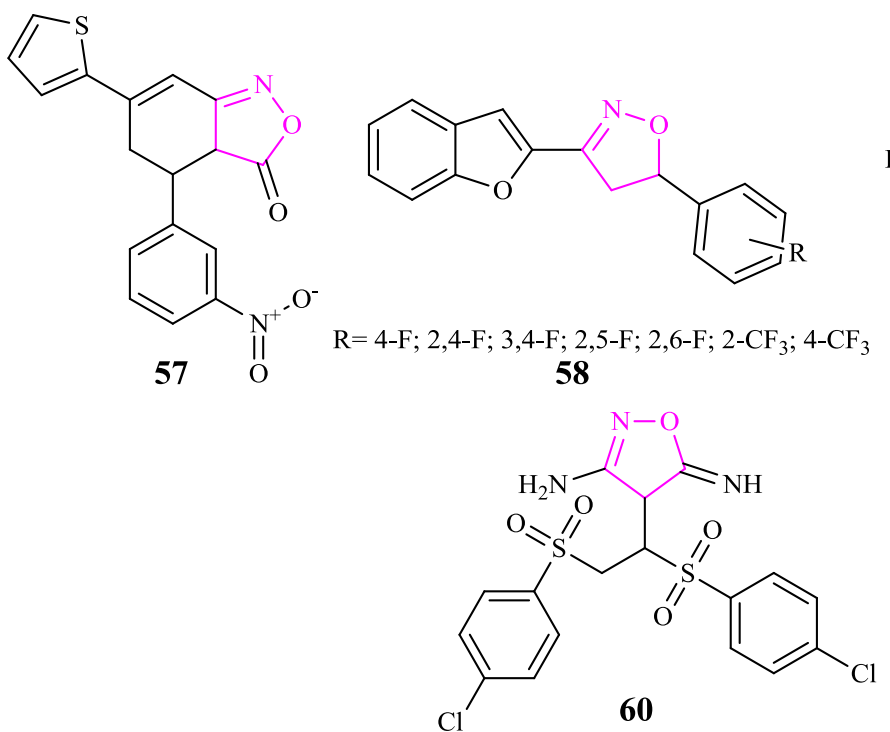

Fig. 11 Isoxazole derivatives showing antimicrobial activity (48-60)

A. niger. Zhao et al. (2017b) synthesized a series of aromatic heterocyclic derivatives and evaluated for in vitro antifungal activity. The compounds containing isoxazole nucleus (53; Fig. 11) improved the activity against Aspergillus spp., in particular. And the compounds having fluoro substituent at 2-position of aryl moiety displayed remarkable activity against Candida spp., C. neoformans, A. fumigatus and fluconazole resistant $C$. albicans strain and exhibited weak inhibition profiles for various isoforms of human cytP450 and excellent blood plasma stability.

The 2,3,5-substituted perhydropyrrolo[3,4- $d$ ] isoxazole4,6-diones (54; Fig. 11) have been synthesized by Agirbas 
et al. (2007) by cycloaddition reaction of N-methyl-Carylnitrones with $\mathrm{N}$-substituted maleimides and screened for antibacterial activity. Most of them exhibited activity against $E$. faecalis and $S$. aureus. Sahu et al. (2009) synthesized a series of novel 4-(5'-substituted-aryl-4',5'-dihydro-isoxazole-3'-yl-amino)phenols $\quad(\mathbf{5 5} ; \quad$ Fig. 11$)$ and screened for in vitro antibacterial activity against $S$. aureus and $S$. typhi and antifungal activity against $C$. albicans and A. niger. Compound bearing 4-Cl phenyl substitution at 5position of isoxazole was found to be most potent antibacterial and antifungal agent of the series. Vaidya et al. (2007) synthesized a series of $N$-substituted-2-(benzo $[d]$ isoxazol-3-ylmethyl)- $1 H$-benzimidazoles and screened for antibacterial activity against $S$. typhimurium and $S$. aureus. Compounds exhibited good activity against $S$. typhimurium while poor activity against $S$. aureus except for compound 56 (Fig. 11) which was highly active even at $1 \mu \mathrm{g} / \mathrm{mL}$. In another series, fused ring isoxazolinones displayed a wide range of antimicrobial activity. In particular, derivative $\mathbf{5 7}$ (Fig. 11) bearing thiophene ring was most potent against B. subtilis and C. albicans (Mazimba et al. 2014).

Chundawat et al. (2014) synthesized some fluorinecontaining heterocycles incorporating benzofuran with dihydroisoxazoles (58; Fig. 11). The compounds were evaluated for their in vitro antibacterial activity against the Gram-positive bacteria $S$. aureus, B. subtilis, S. pneumoniae, $S$. pyogenes, the Gram-negative bacteria E. coli, $P$. aeruginosa, $S$. typhi and antifungal activity against the fungi C. albicans, A. niger, A. clavatus. All the compounds showed moderate to high activity against all tested bacterial strains and C. albicans. Weidner-Wells et al. (2004) synthesized a series of 5-substituted isoxazol-3-yl linked with oxazolidinone and screened for in vitro antimicrobial activity against susceptible and resistant Gram-positive organisms. Several analogs (59; Fig. 11) from this series were comparable to or more potent than linezolid in vitro and also exhibited in vivo activity in a lethal murine infection model but less than linezolid.

Padmaja et al. (2009) synthesized some aminoiminoisoxazole derivatives by Michael condensation of 2-( $1^{\prime}, 2^{\prime}-$ diaroylethyl)malononitrile and 2-(1,2-diarylsulfonylethyl) malononitrile with hydroxylamine hydrochloride. All the compounds possessed excellent antimicrobial activity against Gram-positive bacteria and good activity against Gram-negative bacteria with a maximum for the compound 60 (Fig. 11) having chloro substituent in the aryl moiety. These compounds also exhibited high antioxidant property in both nitric oxide and DPPH methods. Siddiqui et al. (2013) synthesized an isoxazole derivative 61 (Fig. 12) and evaluated for in vitro antibacterial and antifungal activity. It was found to be highly active against $P$. aeruginosa and $A$. niger, moderately active against $B$. subtilis and $E$. coli and poorly active against $S$. aureus. Srinivas et al. (2009) synthesized a series of methylene-bis-4,6-diarylbenzo[ $d]$ isoxazoles and evaluated them against $C$. albicans, $A$. fumigatus, T. rubrum, and T. mentagrophytes. Compounds $\mathbf{6 2}, \mathbf{6 3}$, and 64 (Fig. 12) showed good activity against all the tested fungi that were almost equal to the standard Amphotericin B. The comparison of antifungal activity of dimeric compounds with monomeric compounds revealed that almost all the dimeric compounds showed enhanced activity than their monomeric analogs.

Srinivas et al. (2010) synthesized an another series of methylene-bis-tetrahydro[1,3]thiazolo[4,5-c] isoxazole and evaluated for their antifungal activity against $C$. albicans, A. fumigatus, T. rubrum, and T. mentagrophytes and further for nematicidal activity against D. myceliophagus and C. elegans. The compound 65 (Fig. 12) showed good activity against all the tested fungi, as well as significant nematicidal activity. Liu et al. (2014) synthesized a series of 2-(5-methyl-3-(4-chloro/trifluoromethylphenyl)isoxazol-4yl)-5-arylamino-1,3,4-oxadiazoles and tested for in vitro antifungal activities against $B$. cinerea and $R$. cerealis by the mycelium growth rate method. All the compounds displayed moderate to high activities against $B$. cinerea whereas low activities against $R$. cerealis. Among them compounds 66a, 66b, and 66c (Fig. 12) showed high activities against $B$. cinerea with the $\mathrm{EC}_{50}$ value less than $20 \mu \mathrm{g} / \mathrm{mL}$.

Brahmayya et al. (2013) synthesized some 5-aryl-4-methyl3-yl-(imidazolidin-1-yl-methyl, 2-ylidene nitroimine) isoxazoles $(67$; Fig. 12) and tested them for fungicidal activity against $R$. oryzae, $C$. tropicum and A. niger. The compounds having halogen and methoxy groups emerged as good antifungals. Guo et al. (2015) synthesized 5-isoxazolyl substituted pyrimidine nucleosides and evaluated them for inhibitory activity on the growth of $L$. donovani. Aryl substituted isoxazole nucleosides (68; Fig. 12) showed stronger activity than alkyl substituted isoxazole nucleosides. And for aryl substituted isoxazole nucleosides, methyl and fluoro substituent at 4-position of the phenyl ring of the isoxazole moiety improved the antileishmanial activity. Mares et al. (2002) synthesized 3methyl-5-aminoisoxazole-4-thiocyanate (69; Fig. 12) and studied on the dermatophyte $E$. floccosum. The compound 69 (Fig. 12) strongly inhibited the growth of the fungus in vitro and altered the ultrastructural morphology of the fungus.

\section{Antitubercular activity}

Kachhadia et al. (2004) prepared a series of 1-[p-(3'-chloro2'-benzo(b)thiophenoylamino)-phenyl]-5-aryl-isoxazoles and screened for their antitubercular activity. Compounds 70a, 70b, and 70c (Fig. 13) showed significant activity against MTB $\mathrm{H}_{37} \mathrm{Rv}$. Patel et al. (2014) synthesized coumarin-based isoxazoles and evaluated for their antimycobacterial activity against MTB $\mathrm{H}_{37} \mathrm{Rv}$ using Lownstein-Jensen MIC method. Compound 71 (Fig. 13) 
<smiles>Oc1ccc(Cc2ccc(O)c(-c3cc(-c4ccc(Br)cc4)cc4oncc34)c2)cc1-c1cc([Al])cc2oncc12</smiles><smiles>COC(=O)c1cc(-c2cc3ccccc3o2)on1</smiles><smiles>Cc1ccc(Br)c(Br)c1</smiles><smiles>Cc1cncs1</smiles><smiles>Cc1cnccn1</smiles><smiles></smiles><smiles>[R]c1ccc(Nc2nnc(-c3c(-c4ccc([R16])cc4)noc3C)o2)cc1</smiles>

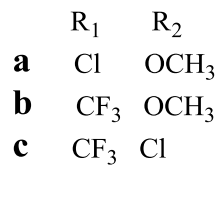<smiles></smiles>

$\mathrm{R}=-\mathrm{H}, 4-\mathrm{Cl}, 4-\mathrm{Br}, 4-\mathrm{F}, 4-\mathrm{CH}_{3}, 4-\mathrm{OCH}_{3}$, $2-\mathrm{Cl}, 2-\mathrm{OCH}_{3}, 3-\mathrm{OCH}_{3}, 3-\mathrm{Cl}$

67

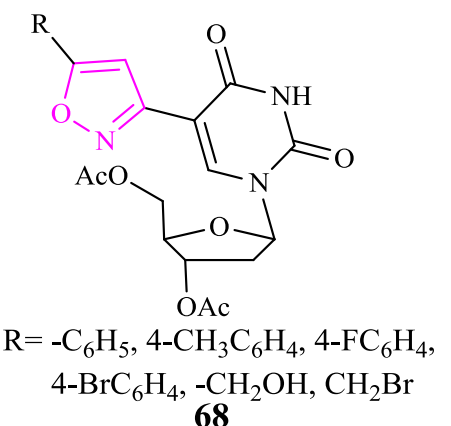

68<smiles>Cc1noc(N)c1[Se]#N</smiles>

69

Fig. 12 Isoxazole derivatives showing antimicrobial activity (61-69)

bearing methoxy group exhibited good antimycobacterial activity with MIC of $62.5 \mu \mathrm{g} / \mathrm{mL}$ and $99 \%$ of inhibition while rest of the compounds showed MIC in the range of $100-1000 \mu \mathrm{g} / \mathrm{mL}$. Changtam et al. (2010) synthesized isoxazole analogs of curcumin and evaluated for antimycobacterial activity. The presence of $p$-methoxy and $p$ hydroxy groups on aromatic ring enhanced the activity. Compound 72 (Fig. 13) with mono- $O$-methyl curcumin isoxazole (MIC $0.09 \mu \mathrm{g} / \mathrm{mL}$ ) was found to be 1131-fold more active than curcumin and approximately 18 and 2-fold more active than standard drugs kanamycin and isoniazid, respectively. Compound 72 (Fig. 13) also displayed high activity against multidrug-resistant MTB clinical isolates (MIC 0.195-3.125 $\mu \mathrm{g} / \mathrm{mL}$ ).
Joshi et al. (2016) synthesized pyrrolyl derivatives with isoxazole moiety and evaluated for activity against MTB. Compound 73 (Fig. 13) exhibited significant activity against $\mathrm{H}_{37} \mathrm{Rv}$ strain and found to be non-toxic when tested for mammalian cell toxicity using A549 cancer cell line. Naidu et al. (2014) synthesized a series of 3-(4-(substituted sulfonyl)piperazin-1-yl)benzo[ $d]$ isoxazole analogs and evaluated for their in vitro antitubercular activity against MTB $\mathrm{H}_{37} \mathrm{Rv}$ strain. All the compounds exhibited MIC between 3.125 and $50 \mu \mathrm{g} / \mathrm{mL}$. Compound 74 (Fig. 13) emerged as the most promising candidate for the series by inhibiting $99 \%$ growth of MTB $\mathrm{H}_{37} \mathrm{Rv}$ strain at a concentration of $3.125 \mu \mathrm{g} / \mathrm{mL}$ and a selectivity of $>130$. 


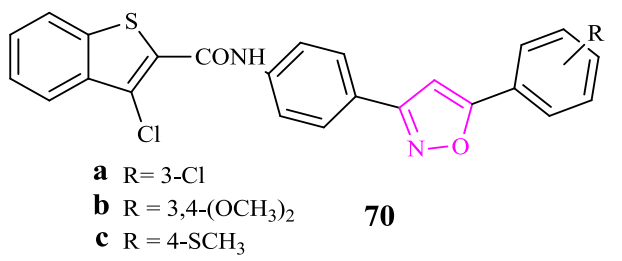<smiles>COc1ccc(-c2cc(-c3ccc(Nc4cc(=O)oc5ccccc45)cc3)no2)cc1OC</smiles>

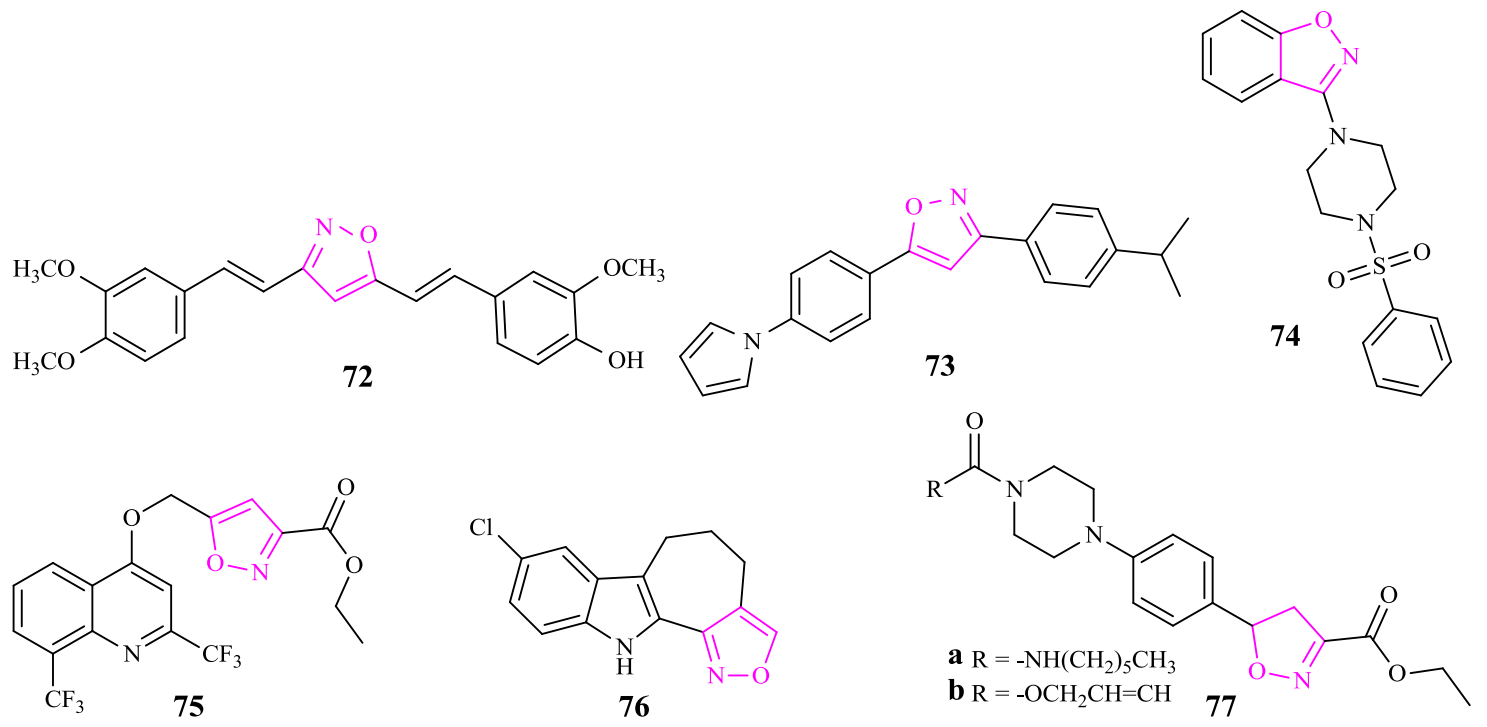

Fig. 13 Isoxazole derivatives showing antitubercular activity (70-77)

Mao et al. (2010) synthesized mefloquine-isoxazole carboxylic esters and evaluated for antitubercular activity. Compound 75 (Fig. 13) was found to possess excellent activity and specificity against MTB $\mathrm{H}_{37} \mathrm{Rv}$ both intracellularly and extracellularly. The ester bio-isosteres of compound 75 were inactive as antitubercular agent suggesting that the ester may be acting as a prodrug. Yamuna et al. (2012) synthesized isoxazolo cyclohepta[$[b]$ indoles and screened for in vitro antimycobacterial against MTB $\mathrm{H}_{37} \mathrm{Rv}$. The maximum activity was found in compound $\mathbf{7 6}$ (Fig. 13) having a chloro substituent in the cyclohepta[b]indole moiety. This compound was found to be non-mutagenic and therefore biologically safe for intake. Rakesh et al. (2009) synthesized 3,5-disubstituted isoxazoline esters and evaluated them for anti-tuberculosis activity. Substitution of isoxazoline C-5 position with piperazyl-urea (77a; Fig. 13) and piperazylcarbamate (77b; Fig. 13) improved anti-tubercular activity. However, replacement of ester group at C-3 position with bioisosteric groups led to complete loss of activity.

\section{Antiviral activity}

Due to the evolution of significant resistance toward antiviral drugs, the development of new drugs possessing potent antiviral activity is critical. Lee et al. (2009) synthesized some 5-isoxazol-5-yl-2'-deoxyuridines (78; Fig. 14) and evaluated their activity against 12 different viruses, namely HSV-1, HSV-2, HIV-1, HIV-2, Encephalomyocarditis virus, Coxsackie B3, vesicular stomatitis, three different influenza viruses (Taiwan, Seoul and Panama) and two corona viruses. All the compounds (78; Fig. 14) exhibited antiviral activities against all the tested virus except HIV, influenza and corona viruses. While some compounds were more active than the reference drugs but they were less selective. Deng et al. (2009) synthesized a series of alkenyldiarylmethanes with a benzo $[d]$ isoxazole ring in place of metabolically unstable methyl ester moiety and screened for anti-HIV activity. All the compounds were found to inhibit HIV-1 Reverse Transcriptase but the compound 79 (Fig. 14) was most promising and a good alternative to hydrolytically unstable methyl esters.

\section{Antidepressant activity}

Patil and Bari (2013) synthesized isoxazolines incorporating indole and evaluated them for antidepressant activity by forced swim test in mice, and their locomotor activity was assessed using actophotometer. All the compounds showed 
Fig. 14 Isoxazole derivatives showing antiviral activity $\mathbf{( 7 8 ,}$ 79)

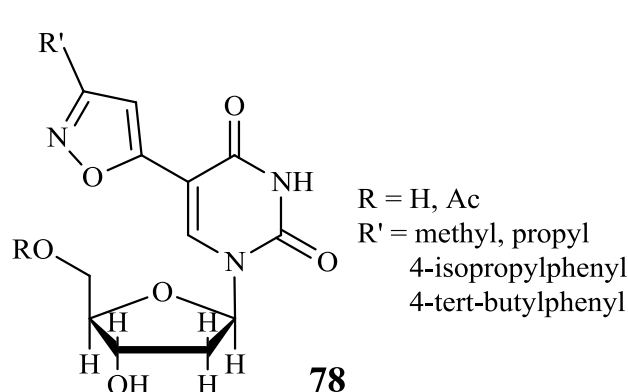

significant antidepressant activity with no significant change in locomotor activity. Compounds 80a and 80b (Fig. 15) emerged as potent antidepressants from this series when compared with reference drugs imipramine and fluoxetine indicating that introduction of an appropriate heterocyclic ring can lead to potent antidepressants. Andrés et al. (2003) reported the synthesis of enantiomeric pairs of 7-amino3a,4-dihydro-3H-[1]benzopyrano[4,3-c]isoxazole derivatives. Compound 81 (Fig. 15) proved to be the most potent $\alpha_{2}$-adrenoceptor blocker with potent serotonin (5-HT) reuptake inhibiting activity and thus acting as antidepressant agents. A further study (Andrés et al. 2007) showed that the compound $\mathbf{8 1}$ (Fig. 15) was more potent as 5-HT reuptake inhibitor than as $\alpha_{2}$-adrenoceptor blocker both after subcutaneous and oral administration.

The $\alpha 4 \beta 2$ nicotinic acetylcholine receptors (nAChRs) are an attractive target for the development of novel antidepressants. Liu et al. (2011) synthesized several isoxazole analogs of Sazetidine-A (82; Fig. 15) by replacing the metabolically unstable acetylene of Sazetidine-A with metabolically stable isoxazole ring. Sazetidine-A interacts with $\alpha 4 \beta 2-n A C h R s$ as a partial agonist and possesses favorable antidepressant profiles. The compound $\mathbf{8 3}$ (Fig. 15) displayed selectivity, as well as excellent antidepressant behavioral activity measured by the mouse forced-swim test. Zhang et al. (2016) synthesized some hybrid compounds by combining substituted isoxazolyl side chains with N-pyridyldiamines as selective partial agonists for $\alpha 4 \beta 2$-nAChRs. Compound 84 (Fig. 15) displayed high binding selectivity towards $\alpha 4 \beta 2$ over $\alpha 3 \beta 4$-nAChRs and significant antidepressant activity in the forced swim test. $\mathrm{Yu}$ et al. (2012) synthesized a series of 5-alkoxy isoxazole as nAChRs ligands. Most of the compounds displayed selectivity for rat $\alpha 4 \beta 2$ over $\alpha 3 \beta 4$-nAChRs. Among them, compound 85 (Fig. 15) was highly selective and displayed potent antidepressant-like activity.

Olesen et al. (1998) synthesized a series of 3-((5-alkylamino-4-isoxazolyl)-1,2,5,6-tetrahydropyridine (86; Fig. 15 ) and evaluated for their affinity and selectivity for central nicotinic receptors. It was found that only the monoalkyl amino-substituted compounds had high affinity and selectivity for the central nicotinic receptors. The affinity increased with increasing the alkyl side chain length up to propyl. Evaluation of these compounds in cell lines expressing nicotinic receptor subtypes showed that the compounds had up to 10 -fold higher affinity for $\alpha 4 \beta 2$ receptor than $\alpha 3 \beta 2$ receptor subtype. Kumar et al. (2017) synthesized a series of 3,4,5-trisubstituted isoxazoles incorporating furan and piperazine moiety and evaluated for their antidepressant activity by Porsolt's forced swimming test on albino mice and antianxiety activity by plus maze method. Compounds 87a and 87b (Fig. 15) displayed significant antidepressant, as well as anti-anxiety activity. The molecular modeling studies showed good binding interactions of these compounds with the MAO-A (Fig. 16).

\section{Anticonvulsant activity}

Enhancement of GABA transmission by inhibiting GABA uptake has been proved to be an effective treatment for convulsions. Falch et al. (1999) synthesized some novel 3hydroxy-4-amino-4,5,6,7-tetrahydro-1,3-benzisoxazole derivatives and screened for GABA inhibitory and anticonvulsant activity. In the series of compounds, $(R)$-enantiomer of $\mathbf{8 8}$ (Fig. 17) in which primary amino group was converted to a secondary amino group, showed potent GABA inhibitory activity and was 12 times more potent as glial GABA uptake inhibitor than of neuronal GABA uptake. However, substitution of N-methyl group with $\mathrm{N}$ ethyl group decreased the glial selectivity. Compound $\mathbf{8 8}$ potently protected Frings mice against audiogenic seizures when administered intracerebroventricularly. A series of $o$ substituted, $m$-substituted and $p$-substituted 4-phenyl-5-(4piperidyl)-3-isoxazolols was synthesized by Frølund et al. (2007) and evaluated for antagonistic activity against $\mathrm{GABA}_{\mathrm{A}}$ receptor, a potential target for the treatment of epilepsy, anxiety and sleep disorders. The $m$-phenyl substituted compounds $(89 \mathbf{a}, \mathbf{8 9}$ ) ) and $p$-phenoxy $(\mathbf{8 9 c})$ substituted compounds (Fig. 17) displayed high affinity and antagonist potencies in the low nanomolecular range.

Clausen et al. (2005) synthesized a series of lipophilic diaromatic derivatives of (R)-4-amino-4,5,6,7-tetrahydrobenzo $[d]$ isoxazol-3-ol and evaluated pharmacologically in vitro and in vivo for anticonvulsant activity. 
<smiles>Cc1cccc(C2=CCCN2)n1</smiles><smiles>COc1cc2c(cc1OC)C1=NO[C@@H](CN3CCN(C/C(C)=C/c4ccc(F)cc4)CC3)[C@H]1CO2</smiles><smiles>OCCCCC#Cc1cncc(OC[C@@H]2CCN2)c1</smiles>

82<smiles>OCCCc1cc(-c2cncc(OC[C@@H]3CCN3)c2)on1</smiles>

83<smiles></smiles><smiles>Cc1cc(OC[C@@H]2CCN2)on1</smiles><smiles>[R]Nc1oncc1C1=CCCN(C)C1</smiles>

$\mathrm{R}=-\mathrm{H}, \mathrm{Me}, \mathrm{Et}, \mathrm{Pr}, \mathrm{Bu}, \mathrm{C}_{6} \mathrm{H}_{5}$

86<smiles>[R]c1ccc(C2ON=C(c3ccco3)C2CN2CCN(C)CC2)cc1</smiles>

Fig. 15 Isoxazole derivatives showing antidepressant activity (80-87)
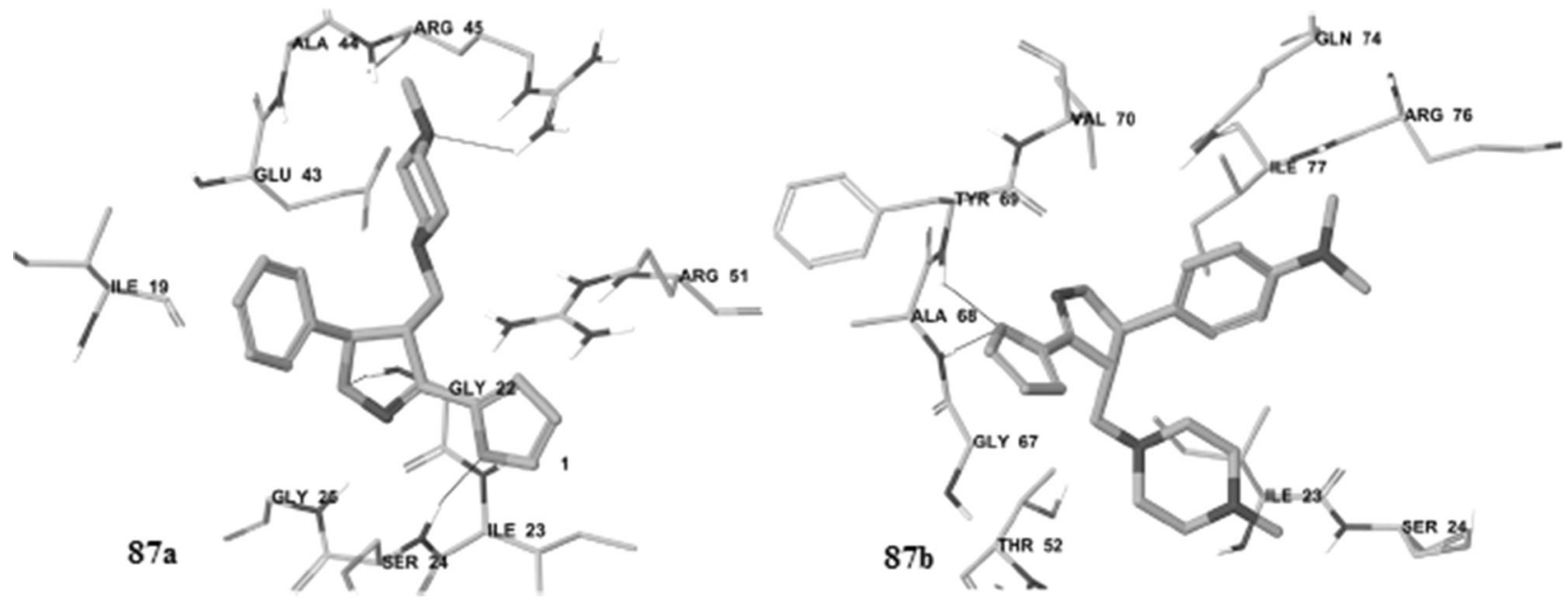

Fig. 16 Binding pattern and interaction of $\mathbf{8 7} \mathbf{a}$ and $\mathbf{8 7} \mathbf{b}$ at MAO-A (Kumar et al. 2017) 
<smiles>CNC1CCCc2onc(O)c21</smiles>

88

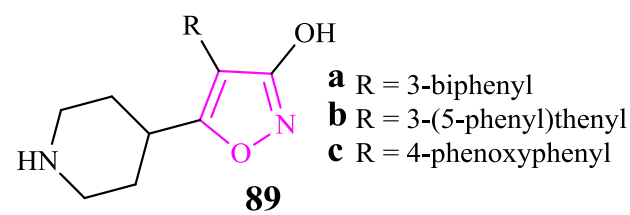

89<smiles>Cc1ccsc1C(=CCCN(C)C1CCCc2onc(O)c21)c1sccc1C</smiles><smiles>O=C1CC(c2noc3ccccc23)C(=O)N1[18O]</smiles>

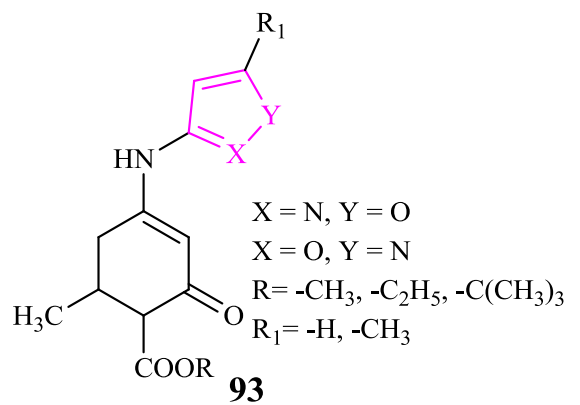<smiles>Nc1nc(-c2ccccc2)nnc1C(=O)N1CCCC1c1noc2cc(F)ccc12</smiles>

92

$(88-93)$

The compounds were effective as GABA uptake inhibitors and anticonvulsants showing that these compounds can cross BBB. The compound 90 (Fig. 17) appeared to be potent at GABA transporter 1 and 2. Malik et al. (2014) synthesized a series of 3-(benzo[ $d]$ isoxazol-3-yl)- $N$-substituted pyrrolidine-2,5-dione and screened through MES and scPTZ tests to find compounds affording protection against human generalized tonic-clonic seizures and generalized absence tonic-clonic seizures, respectively. Compound 91a and 91b (Fig. 17) were found to be most potent antiepileptogenic agents against MES and scPTZ tests, respectively.

Malik and Khan (2014) synthesized a series of (5-amino3-substituted-1,2,4-triazin-6-yl) (2-(6-halo-substituted benzo[ $d]$ isoxazol-3-yl)pyrrolidin-1-yl)methanone derivatives and evaluated their anticonvulsant activities by the MES test. Compound 92 (Fig. 17) was found to be most potent and had the binding affinity with sodium channels in vitro. Eddington et al. (2002) synthesized a series of enaminones derived isoxazoles 93 (Fig. 17) by condensation of 1,3-diketo esters with 3- and 5-amino isoxazoles that led to a series of potent anti-maximal electroshock analogs.

\section{Anti-Alzheimer activity}

Huang et al. (2015) synthesized a series of azacyclic compounds with 5-substituted isoxazoline groups and evaluated their mAChR agonistic potential. A tetrahydropyridine compound 94 (Fig. 18) substituted with 5(2-pyrrolidin-1-yl)isoxazoline at 3-position exhibited potent and selective mAChR agonist activity. The compound 94 (Fig. 18) also possessed a disease-modifying role in Alzheimer's disease. Gutiérrez et al. (2013) synthesized some 3,5-disubstituted isoxazole derivatives, tested for their in vitro AChE inhibitory activity and performed their docking study. Compounds 95 and 96 (Fig. 18) emerged as potent AChE inhibitors. Anand and Singh (2012) synthesized pyrrolo-isoxazole benzoic acid derivatives as potential AChE for the management of Alzheimer's disease. All the derivatives displayed potent in vitro AChE inhibitory activity. Compound 97 (Fig. 18) was found to be most active which also ameliorated the scopolamine-induced amnesia in mice. JNK3 is exclusively found in the brain and play an important role in the brain to mediate neurodegeneration such as beta-amyloid 
<smiles>CN1CC=CC(C2=NOC(N3CCCC3=O)C2)C1</smiles><smiles>COc1ccc(C2C3C(=O)N(c4ccc(C(=O)O)cc4)C(=O)C3ON2c2ccc(C)cc2)cc1</smiles><smiles>Cc1ccc(C2=NOC(c3ccc(Cl)c(Cl)c3)C2)cc1</smiles>

Fig. 18 Isoxazole derivatives showing antialzheimer's activity (94-99)

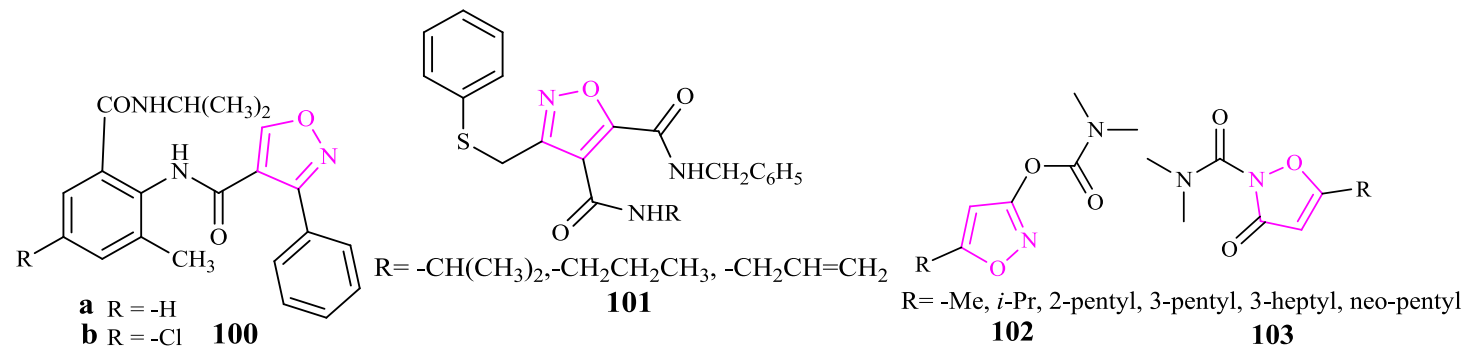

Fig. 19 Isoxazole derivatives showing insecticidal activity (100-103)

processing and neuronal apoptosis in Alzheimer's disease. Compounds with JNK3 inhibitory activity and selectivity over p38 can be potential therapeutics for neurodegeneration disorders as p38 inhibition leads to serious toxic effects. He et al. (2014) developed isoxazoles (98; Fig. 18) with improved JNK3 selectivity over p38 to treat neurodegenerative disorders. Meleddu et al. (2017) synthesized a series of 3,5-diaryl-4,5-dihydroisoxazoles to find MAO-B selective inhibitors to act as neuroprotective agents. None of the compounds inhibited MAO-A and compound 99 (Fig. 18) with a 3,4-dichlorophenyl moiety at position-5 of the dihydroisoxazole ring was the most active on MAO-B.

\section{Insecticidal activity}

Peng-fei et al. (2012) synthesized some novel phenyl substituted isoxazole carboxamides and evaluated for insecticidal activities against Mythimna separate (oriental armyworm). All the compounds showed moderate insecticidal activity, out of which compounds 100a and 100b (Fig. 19) showed comparatively higher activities. SAR studies revealed that a combination of both aliphatic and aromatic amide moieties could improve the insecticidal activity. Yu et al. (2009) prepared a series of 3-(arylthiomethyl)isoxazole-4,5-carboxamides (101; Fig. 19) and evaluated for insecticidal activity using high-throughput screening (HTS) against Spodoptera exigua (beet armyworm) and A. aegypti (yellow fever mosquito). The results confirmed that 3,4,5-trisubstituted isoxazoles present a bioactive scaffold that can be utilized to design novel insecticides. To identify potential selective and resistancebreaking mosquitocides against the African malaria vector Anopheles gambiae, Verma et al. (2015) investigated the AChE inhibitory and mosquitocidal properties of isoxazol-3-yl dimethylcarbamates (102; Fig. 19), and the 


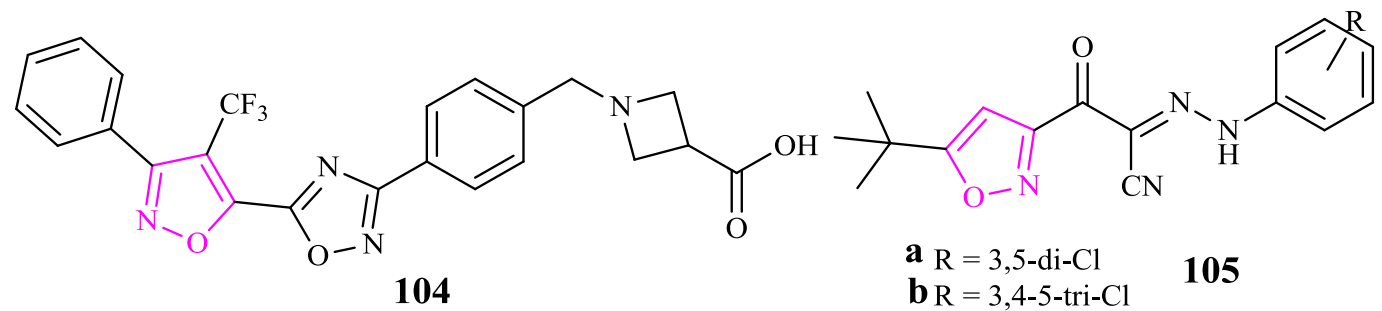<smiles>Cc1nc(-c2ccccc2)c2onc(-c3nnc(C(=O)NCc4cccnc4)o3)c2n1</smiles>

106<smiles>Nc1c(-c2nnc(C(=O)NCc3ccncc3)o2)noc1C(=O)c1ccccc1</smiles>

107

Fig. 20 Isoxazole derivatives showing immunosuppressant activity (104-107)

corresponding 3-oxoisoxazole-2(3H)-dimethylcarboxamide isomers (103; Fig. 19). In both series, compounds were found with excellent contact toxicity to wild-type susceptible (G3) strain and multiply resistant (Akron) strain mosquitoes that carry the G119S resistance mutation of AChE.

\section{Immunosuppressant activity}

Agonism of $\mathrm{S}_{1} \mathrm{P}_{1}$, in particular, has been shown to play a significant role in lymphocyte trafficking from the thymus and secondary lymphoid organs, resulting in immunosuppression. Watterson et al. (2016) synthesized a series of isoxazoles derived from isoxazole-3-carboxylic acids and isoxazole-5-carboxylic acids to develop selective $\mathrm{S}_{1} \mathrm{P}_{1}$ selective agonists. Compound 104 (Fig. 20) was emerged as a lead compound with good efficacy when administered orally in a rat model of arthritis $\left(\mathrm{ED}_{50} 0.05 \mathrm{mg} / \mathrm{Kg}\right)$ and a mouse experimental autoimmune encephalomyelitis model of multiple sclerosis $\left(\mathrm{ED}_{50} 0.05 \mathrm{mg} / \mathrm{Kg}\right)$. EPACs are involved in regulating a wide variety of intracellular physiological and pathophysiological processes like T-cell mediated immunosuppression (Almahariq et al. 2015).
Ye et al. (2015) synthesized a series of 2-(isoxazol-3-yl)2-oxo- $N$ '-phenyl-acetohydrazonoyl cyanide as EPAC antagonists. Compounds 105a and 105b (Fig. 20) have emerged as potential EPAC1 and EPAC2 inhibitors. The SAR studies revealed that further modifications at the 3positions, 4-positions, 5-positions of the phenyl scaffold and the 5-position of the isoxazole moiety might give more potent EPAC antagonists. Wagner et al. (2008) synthesized isoxazolo[4,5- $d]$ pyrimidine and tested for their effects on immune response in the mouse model. Compound 106 (Fig. 20) emerged as a universal inhibitor of immune response while compound 107 (Fig. 20) selectively suppressed the humoral immune response.

\section{Antihyperglycemic, antiobesity, or hypolipidemic activity}

Kafle and co-workers (Kafle et al. 2011; Kafle and Cho 2012) synthesized a series of isoxazolones to develop a potent inhibitor of PTP1B as an antiobesity and antihyperglycemic agent. PTP1B inhibition leads to prolongation of tyrosine phosphorylated stats of insulin and leptin receptors resulting in suppression of weight gain and 
<smiles>[R]CCOc1cc(OC)ccc1-c1cc(-c2ccccc2)no1</smiles><smiles>COc1ccc(NC(=O)Nc2ccc(-c3cc(C(=O)NC(C(=O)O)C(C)C)on3)cc2)cc1</smiles><smiles>Cn1cc(C(=O)O)c2ccc(N3CCC(OCc4c(-c5c(Cl)cccc5Cl)noc4C4CC4)CC3)cc21</smiles>

Fig. 21 Isoxazole derivatives showing antihyperglycemic, antiobesity or hypolipidemic activity (108-112)

augmentation of insulin sensitivity. Among them, compound 108 (Fig. 21) was the most potent and selective inhibitor of PTP1B with an $\mathrm{IC}_{50}$ of $2.3 \mu \mathrm{M}$ and can be considered as a promising lead compound for the control of obesity and hyperglycemia. Kumar et al. (2009) synthesized 3,5-diaryl isoxazole derivatives and screened them for in vivo antihyperglycemic and lipid-lowering activity. Some of the synthesized compounds 109 (Fig. 21) showed promising antihyperglycemic activity with moderate lipid-lowering activity. These compounds did not show any significant activity in PPAR and DPP-4 assay but exhibited the promising PTP1B inhibitory activity which revealed their mode of action. Jadhav et al. (2012) synthesized a series of compounds containing 3-phenyl isoxazoles and evaluated them for DGAT1 which is a promising target enzyme for obesity due to its involvement in the rate determining step of triglyceride biosynthesis. Compound 110 (Fig. 21) with an in vivo triglyceride reduction of $90 \%$ and $\mathrm{IC}_{50}$ of $64 \mathrm{nM}$ emerged as a promising anti-obesity agent.
Mokale et al. (2014) synthesized a series of 2-methyl2-(substituted phenyl isoxazol)phenoxyacetic acid derivatives and evaluated them for in vivo hypolipidemic activity by triton induced hyperlipidemia in rats. Most of the compounds had the ability to lower the elevated lipid levels, amongst which 111a; 111b, and 111c (Fig. 21) were found to be most active as compared to standard drug Fenofibrate. Further SAR studies revealed that isoxazole ring is important for hypolipidemic activity. FXR has been reported to have profound effects on plasma lipids in the animal model. Genin et al. (2015) discovered piperidinylisoxazole system as selective FXR agonist in vitro which showed robust lipid modulating properties lowering LDL and triglycerides while raising HDL in preclinical species and. The molecule LY2562175 (112; Fig. 21) is ultimately advanced to the clinical evaluation in humans due to its excellent lipid modulation profile in rodents, as well as acceptable pharmacokinetic properties. 
Fig. 22 Isoxazole derivatives showing dopamine transporter inhibitor activity $(\mathbf{1 1 3}, \mathbf{1 1 4})$

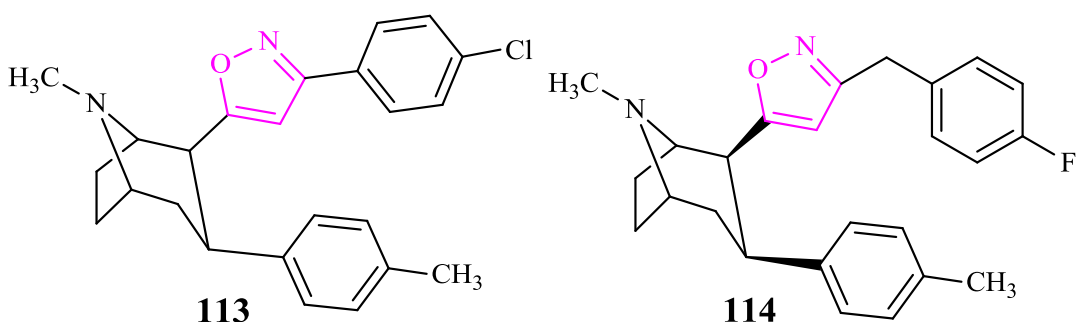<smiles>Cc1c(C)c2c(c(C)c1O)C=CC(C)(COCc1cc(-c3ccc(O)cc3)no1)O2</smiles>

115

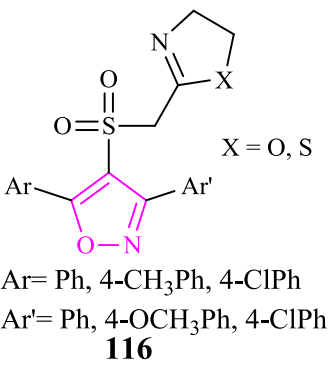

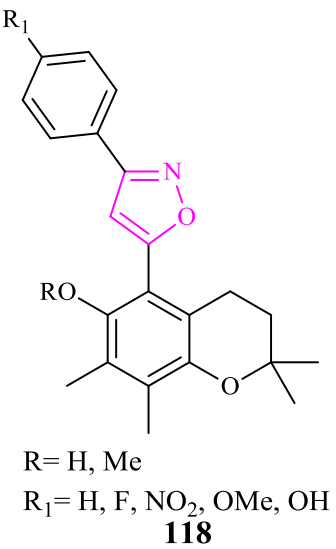<smiles>[R8]c1ccc(-c2cc(C3(C)CCc4c(C)c(O)c(C)c(C)c4O3)on2)cc1</smiles><smiles>[R]Oc1ccc(/C=C/c2cc(/C=C/c3ccccc3)on2)cc1</smiles>

117

$$
\begin{aligned}
& \mathrm{R}=\mathrm{H}, \mathrm{Me} \\
& \mathrm{R}_{1}=\mathrm{H}, \mathrm{OMe}
\end{aligned}
$$

Fig. 23 Isoxazole derivatives showing antioxidant or antiageing activity (115-119)

\section{Dopamine transporter inhibitory activity}

Carroll et al. (2004) synthesized several 3 $\beta$-(substituted phenyl)-2 $\beta$-(3-substituted isoxazol-5-yl)tropanes and evaluated for their ability to inhibit radioligand binding at the monoamine (dopamine, serotonin and norepinephrine) transporters for the treatment of cocaine abuse. Most of the analogs were dopamine transporter selective, increase locomotor activity with slow onset and long duration of action. But the high dopamine transporter selective compound $\mathbf{1 1 3}$ (Fig. 22) surprisingly did not increase the locomotor activity that could be due to lack of brain penetration. Similarly, Jin et al. (2008) synthesized a series of $2 \beta$-[3'-(substituted benzyl)isoxazol-5-yl]- and 2 $\beta$-[3'-methyl-4'-(substituted phenyl) isoxazol-5-yl]-3 $\beta$-(substituted phenyl)tropanes. These compounds were evaluated for affinities at monoamine (dopamine, serotonin and norepinephrine) transporters for the treatment of cocaine abuse. All the tested compounds were found to be relatively selective for dopamine transporter. The compounds of former series exhibited 3-fold to 25-fold higher affinities at dopamine transporter. Among them, compound 114 (Fig. 22) was most potent and dopamine transporter selective analog.

\section{Antioxidant/antiageing activity}

Koufaki et al. (2014) synthesized a series of 3,5-disubstituted isoxazoles and evaluated their cytoprotective and antiageing properties in terms of stress resistance in human primary fibroblasts (in vitro model) and with the extended longevity of the nematode $C$. elegans (in vivo model). Compound 115 (Fig. 23) bearing a phenolic group and a 6$\mathrm{OH}$ chroman group was revealed to be a potent antioxidant and anti-ageing agent. Padmaja et al. (2011) prepared bis 
Fig. 24 Isoxazole derivatives showing antistress activity $(\mathbf{1 2 0}$ 122)<smiles>COc1ccc(C2=NOC(Cc3ccc(OCCN4CCCCC4)c(OC)c3)C2)c(OC)c1</smiles>

122<smiles>[R]Oc1ccc(C[C@@H](C)NC[C@@H](O)c2cc(Br)no2)cc1</smiles>

$\mathrm{R}=\mathrm{CH}_{2} \mathrm{COOH}, \mathrm{CH}_{2} \mathrm{COOEt},\left(\mathrm{CH}_{2}\right)_{3} \mathrm{CH}_{3}$

123<smiles>Clc1cc(Cl)c(Oc2ccc(C3=NOC(c4ccccc4)C3)cc2)nc1Oc1ccc(C2=NOC(c3ccccc3)C2)cc1</smiles>

124<smiles>Clc1cc(Cl)c(Oc2cccc(C3=NOC(c4ccccc4)C3)c2)nc1Oc1ccccc1</smiles>

125

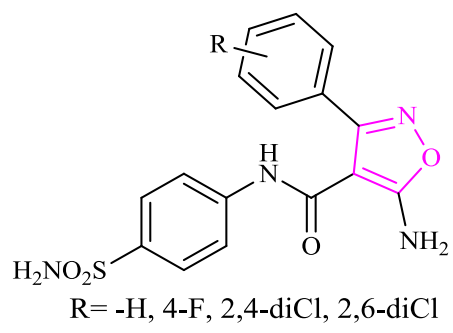

128<smiles>CC(OC(=O)Nc1conc1-c1ccc(CSCCC(=O)O)cc1)C1=C(Cl)CCC1</smiles><smiles>[R]</smiles><smiles>[R]c1ccc(C2NC(=O)C3ONC(=O)C3N2)cc1</smiles>

a $\mathrm{R}=-\mathrm{H}$
b $\mathrm{R}=-\mathrm{F}$

127

Fig. 25 Isoxazole derivatives showing miscellaneous activity (123-129)

heterocycles-oxazolyl/thiazolylsulfonylmethyl isoxazoles (116; Fig. 23) and evaluated for antioxidant activity. It was observed that the compounds having isoxazole in combination with oxazoline exhibited high antioxidant activity. The presence of electron donating substituent on the aromatic ring enhanced the activity.

Sherin and Rajashekharan (2016) synthesized 3,5-bis (styryl)isoxazoles (117; Fig. 23) derived from curcuminoids by mechanochemical grinding of the curcuminoids with hydroxylamine hydrochloride catalyzed by glacial acetic acid and evaluated for antioxidant activity by DPPH, FRAP and $\beta$-carotene assays. The presence of hydroxyl and methoxy groups on the terminal aryl moieties of 3,5-bis (styryl)isoxazoles improved the antioxidant activity. Koufaki et al. (2011) synthesized a series of 2-isoxazolyl or 5isoxazolyl chromans $(\mathbf{1 1 8}, \mathbf{1 1 9}$; Fig. 23) with the aim to 


\begin{tabular}{|c|c|c|c|}
\hline Activity & Groups at 3-position & Groups at 4-position & Groups at 5-position \\
\hline Analgesic & Methyl, carboxy & Unsubstituted & Substituted phenyl \\
\hline Anti-inflammatory & Substituted phenyl & Substituted phenyl, pyridine & Indole, isopropyl \\
\hline Anticancer & Substituted phenyl, furan, indole & Unsubstituted, arylsulfonyl, arylamido & $\begin{array}{l}\text { Amino, arylamido, substituted phenyl, } \\
\text { indole, thiazole, quinoline }\end{array}$ \\
\hline Antimicrobial & $\begin{array}{l}\text { Substituted phenyl, thiophene, } \\
\text { benzofuran, amino }\end{array}$ & $\begin{array}{l}\text { Arylsulfonyl, thiocyanate, 2-amino } \\
\text { oxadiazole }\end{array}$ & $\begin{array}{l}\text { Amino, halogen substituted phenyl, } \\
\text { thienyl, thiazole }\end{array}$ \\
\hline Antidepressant & Pyridine, pyrrole & Unsubstituted, piperazine & Indole, pyridine, substituted amine \\
\hline Anticonvulsant & Hydroxyl, pyrrolidine & Substituted phenyl & piperidyl \\
\hline Anti-Alzheimer & Substituted phenyl, pyridine & Unsubstituted, pyrazole & $\begin{array}{l}\text { Substituted phenyl, Long chain alkyl, } \\
\text { cyclohexene, pyrrolidine }\end{array}$ \\
\hline Immunosuppressant & Substituted aryl & Unsubstituted, trifluoromethyl, amino & tert-butyl, oxadiazole \\
\hline
\end{tabular}

discover neuroprotective agents with much lower cytotoxicity. The neuroprotective activity was evaluated against oxidative stress-induced death of neuronal $\mathrm{H} 22$ cells (mouse hippocampal cell line). The majority of them displayed high in vitro neuroprotective activity with $\mathrm{EC}_{50}$ below $1 \mu \mathrm{M}$ and lacked cytotoxicity.

\section{Antistress activity}

Badru et al. (2012) synthesized a series of pyrroloisoxazole derivatives via 1,3-dipolar cycloaddition of azomethine $\mathrm{N}$-oxides with $\mathrm{N}$-( $\alpha$-naphthyl)maleimide. Compound 120 (Fig. 24) exhibited significant anti-stress activity in immobilization stress-induced increase in nonsocial behavior. Maurya et al. (2011) synthesized 3,5-disubstituted isoxazolines and evaluated their anti-stress potential under acute stress condition in relation to peripheral and biochemical changes. Some compounds 121 and 122 (Fig. 24) displayed protective effects against acute stress-induced elevation in gastric ulceration, adrenal hypertrophy, hyperglycemia, plasma creatine kinase activity, and corticosterone levels.

\section{Miscellaeneous activities}

Dallanoce et al. (2007) synthesized three pairs of stereoisomeric 3-bromo-isoxazolyl amino alcohol derivatives $\mathbf{1 2 3}$ (Fig. 25) and evaluated for their binding affinity at human $\beta_{1}$-ARs, $\beta_{2}$-ARs, and $\beta_{3}$-ARs in membranes from Chinese hamster ovary cells stably transfected with the respective receptor subtype. The highest efficacy (70-90\%) was observed at $\beta_{2}$-ARs whereas all compounds behaved as partial agonists $(30-60 \%)$ at the $\beta_{3}$-subtype and the lowest (15-35\%) was found at $\beta_{1}$ subtype. Shailaja et al. (2011) synthesized a series of 3,5-disubstituted-4,5-dihydroisoxazoles and 3,4,5-trisubstituted isoxazoles and evaluated for their action on isolated frog heart. All the test compounds moderately reduced the heart rate, cardiac output, and force of contraction and compounds 124 and 125 (Fig. 25) showed better inhibition of sodium exchange ion on isolated frog heart studies.

Yamamoto et al. (2007) synthesized isoxazole derivatives and evaluated for LPA antagonistic activity to find potent drugs to treat liver fibrosis. Compound 126 (Fig. 25) exhibited high inhibitory activity at LPA receptor and was expected to be a potent drug candidate for the treatment of liver fibrosis. Wagner et al. (2004) synthesized 5-alkyl and 5-arylisoxazolo[4,5- $d$ ]pyrimidinones structurally similar to hypoxanthine and evaluated for anxiolytic activity. Compounds 127a and 127b (Fig. 25) displayed the approximately same anxiolytic activity as that of diazepam at the non-sedative dose.

Altug et al. (2017) synthesized a series of sulfonamide based 5-amino isoxazole derivatives (128; Fig. 25) and screened for their CA inhibitory properties against four human isoforms: hCA I, hCA II, hCA IV, and hCA VII. All the compounds exhibited excellent inhibitory activity against the cytosolic isoform hCA II, an antiglaucoma drug target. Batra et al. (2002) utilized 3-substituted-phenyl-5isoxazole carboxaldehydes to generate isoxazole-based combinatorial libraries on solid phase through automation. All the compounds were evaluated for their antithrombotic activity in vivo. Compound 129 (Fig. 25) was found to be most potent with $90 \%$ protection against bleeding time. 


\section{Conclusion}

The present review demonstrates the synthesis and structural modifications of isoxazoles. Isoxazole is a versatile building block in many biologically active compounds, and its easy synthesis offers the structure activity studies of various substitutions on this pharmacophore as illustrated in Table 2. This review is endeavoring to find potential future directions in the development of more potent and specific analogs of isoxazole-based compounds for the biological target. The information of the isoxazole based heterocycles illustrated in this review will not only update medicinal chemists with recent findings of biological activities of isoxazoles but also encourage them to use this promising scaffold for the design of novel molecules to identify many more biologically active isoxazoles for the benefit of humanity.

Acknowledgements The authors thank the authorities of GLA University, Mathura, India for their praise worthy inspiration and constant encouragement.

\section{Compliance with ethical standards}

Conflict of interest The authors declare that they have no conflict of interest.

\section{References}

Abushanab E, Lee DY, Goodman L (1973) Synthetic studies in the 1soxazolo[4,5- b] pyrazine system. J Heterocycl Chem 10:181-185

Agirbas H, Guner S, Budak F, Keceli S, Kandemirli F, Shvets N, Kovalishyn V, Dimoglo A (2007) Synthesis and structure-antibacterial activity relationship investigation of isomeric 2,3,5-substituted perhydropyrrolo[3,4-d]isoxazole-4,6diones. Bioorg Med Chem 15:2322-2333

Allegretti PA, Ferreira EM (2013) Platinum-catalyzed cyclizations viacarbene intermediates: syntheses of complementary positional isomers of isoxazoles. Chem Sci 4:1053-1058

Almahariq M, Mei FC, Wang H, Cao AT, Yao S, Soong L, Sun J, Cong Y, Chen J, Cheng X (2015) Exchange protein directly activated by cAMP modulates regulatory T-cell-mediated immunosuppression. Biochem J 465:295-303

Altug C, Güneş H, Nocentini A, Monti SM, Buonanno M, Supuran CT (2017) Synthesis of isoxazole-containing sulfonamides with potent carbonic anhydrase II and VII inhibitory properties. Bioorg Med Chem 25:1456-1464

Amir M, Javed SA, Kumar H (2010) Design and synthesis of 3-[3(substituted phenyl)-4-piperidin-1-ylmethyl/-4-morpholin-4ylmethyl-4,5-dihydro-isoxazol-5-yl]-1H-indoles as potent antiinflammatory agents. Med Chem Res 19:299-310

Anand P, Singh B (2012) Synthesis and evaluation of novel 4[(3H,3aH,6aH)-3-phenyl)-4,6-dioxo-2-phenyldihydro-2H-pyrrolo [3,4-d]isoxazol-5 $(3 \mathrm{H}, 6 \mathrm{H}, 6 \mathrm{aH})$-yl]benzoic acid derivatives as potent acetylcholinesterase inhibitors and anti-amnestic agents. Bioorg Med Chem 20:521-530

Andrés JI, Alcázar J, Alonso JM, Alvarez RM, Bakker MH, Biesmans I, Cid JM, De Lucas AI, Drinkenburg W, Fernández J, Font LM,
Iturrino L, Langlois X, Lenaerts I, Martínez S, Megens AA, Pastor J, Pullan S, Steckler T (2007) Tricyclic isoxazolines: Identification of R226161 as a potential new antidepressant that combines potent serotonin reuptake inhibition and $\alpha 2$-adrenoceptor antagonism. Bioorg Med Chem 15:3649-3660

Andrés JI, Alcázar J, Alonso JM, Alvarez RM, Cid JM, De Lucas AI, Fernández J, Martínez S, Nieto C, Pastor J, Bakker MH, Biesmans I, Heylen LI, Megens AA (2003) Synthesis of 3a,4-dihydro$3 \mathrm{H}-[1]$ benzopyrano[4,3-c]isoxazoles, displaying combined 5-HT uptake inhibiting and $\alpha 2$-adrenoceptor antagonistic activities: a novel series of potential antidepressants. Bioorg Med Chem Lett 13:2719-2725

Andrzejak V, Millet R, Bakalia JEl, Guelzimb A, Gluszoka S, Chavattec P, Bonted J-P, Vaccher Claude, Lipka E (2010) Synthesis of 2, 3 and 4, 5-Dihydro-hydroxy-isoxazoles and Isoxazoles Under Different pH Conditions. Lett Org Chem 7:32-38

Badru R, Anand P, Singh B (2012) Synthesis and evaluation of hexahydropyrrolo[3,4-d]isoxazole-4,6-diones as anti-stress agents. Eur J Med Chem 48:81-91

Banoglu E, Çelikoglu E, Volker S, Olgac A, Gerstmeier J, Garscha U, Caliskan B, Schubert US, Carotti A, Macchiarulo A, Werz O (2016) 4,5-Diarylisoxazol-3-carboxylic acids: A new class of leukotriene biosynthesis inhibitors potentially targeting 5-lipoxygenaseactivating protein (FLAP). Eur J Med Chem 113:1-10

Bargiotti A, Musso L, Dallavalle S, Merlini L, Gallo G, Ciacci A, Giannini G, Cabri W, Penco S, Vesci L, Castorina M, Milazzo FM, Cervoni ML, Barbarino M, Pisano C, Giommarelli C, Zuco V, De Cesare M, Zunino F (2012) Isoxazolo(aza)naphthoquinones: A new class of cytotoxic Hsp90 inhibitors. Eur J Med Chem 53:64-75

Bartzatt R (2014) Drug analogs of COX-2 selective inhibitors lumiracoxib and valdecoxib derived from in silico search and optimization. Antiinflamm Antiallergy Agents Med Chem 13:17-28

Baruchello R, Simoni D, Marchetti P, Rondanin R, Mangiola S, Costantini C, Meli M, Giannini G, Vesci L, Carollo V, Brunetti T, Battistuzzi G, Tolomeo M, Cabri W (2014) 4,5,6,7-Tetrahydro-isoxazolo-[4,5-c]-pyridines as a new class of cytotoxic Hsp90 inhibitors. Eur J Med Chem 76:53-60

Basha SS, Divya K, Padmaja A, Padmavathi V (2015) Synthesis and antimicrobial activity of thiazolyl pyrazoles and isoxazoles. Res Chem Intermed 41:10067-10083

Batra S, Srinivasan T, Rastogi SK, Kundu B, Patra A, Bhaduri AP, Dixit M (2002) Combinatorial synthesis and biological evaluation of isoxazole-based libraries as antithrombotic agents. Bioorg Med Chem Lett 12:1905-19508

Bourbeau MP, Rider JT (2006) A convenient synthesis of 4-alkyl-5aminoisoxazoles. Org Lett 8:3679-3680

Brahma S, Ray JK (2008) Synthesis of Azirines Containing Aldehyde Functionality and their Utilization as Synthetic Tools for Five Membered Oxazoles and Isoxazoles. J Heterocycl Chem 45:311-317

Brahmayya M, Venkateswararao B, Krishnarao D, Durgarao S, Prasad UV, Damodharam T, Mishra R (2013) Synthesis and fungicidal activity of novel 5-aryl-4-methyl-3yl (imidazolidin-1yl methyl, 2ylidene nitro imine) isoxazoles. J Pharm Res 7:516-519

Bulanov DA, Novokshonova IA, Novokshonov VV, Ushakov IA, Sterkhova IV (2017) Facile one-pot synthesis of 5-substituted isoxazoles and pyrazoles via microwave- promoted intramolecular cyclization of $\gamma$-hydroxyalkynal oximes and hydrazones. Synth Commun 47:335-343

Buoli M, Grassi S, Ciappolino V, Serati M, Altamura AC (2017) The use of zonisamide for the treatment of psychiatric disorders: A Systematic Review. Clin Neuropharmacol 40:85-92

Burkhard JA, Tchitchanov BH, Carreira EM (2011) Cascade formation of isoxazoles: Facile base-mediated rearrangement of substituted oxetanes. Angew Chem-Int Ed 50:5379-5382 
Buron C, El Kaim L, Uslu A (1997) A new straightforward formation of aminoisoxazoles from isocyanides. Tetrahedron Lett 38:8027-8030

Carroll FI, Pawlush N, Kuhar MJ, Pollard GT, Howard JL (2004) Synthesis, monoamine transporter binding properties, and behavioral pharmacology of a series of $3 \beta$-(substituted phenyl)-2 $\beta-(3$ substituted isoxazol-5-yl)tropanes. J Med Chem 47:296-302

Changtam C, Hongmanee P, Suksamrarn A (2010) Isoxazole analogs of curcuminoids with highly potent multidrug-resistant antimycobacterial activity. Eur J Med Chem 45:4446-4457

Chavan AP, Pinjari AB, Mhaske PC (2015) An efficient synthesis of 4-arylmethylidene-3-substituted-isoxazol-5(4h)-ones in aqueous medium. J Heterocycl Chem 52:1911-1915

Chen D, Shen A, Li J, Shi F, Chen W, Ren J, Liu H, Xu Y, Wang X, Yang X, Sun Y, Yang M, He J, Wang Y, Zhang L, Huang M, Geng M, Xiong B, Shen J (2014) Discovery of potent N-(isoxazol-5-yl)amides as HSP90 inhibitors. Eur J Med Chem 87:765-781

Chikkula KV, Raja S (2017) Isoxazole-A potent pharmacophore. Int J Pharm Pharm Sci 9:13-24

Chouaïb K, Romdhane A, Delemasure S, Dutartre P, Elie N, Touboul D, Ben jannet H, Ali Hamza M (2016) Regiospecific synthesis, anti-inflammatory and anticancer evaluation of novel 3,5-disubstituted isoxazoles from the natural maslinic and oleanolic acids. Ind Crops Prod 85:287-299

Chundawat TS, Sharma N, Bhagat S (2014) Synthesis and in vitro antimicrobial evaluation of novel fluorine-containing 3-benzofuran-2-yl-5-phenyl-4,5-dihydro-1H-pyrazoles and 3-benzofuran2-yl-5-phenyl-4,5-dihydro-isoxazoles. Med Chem Res 23:1350-1359

Claisen L (1903) Zur Kenntniss des Propargylaldehyds und des Phenylpropargylaldehyds. Ber der Dtsch Chem Ges 36:3664-3673

Clausen RP, Moltzen EK, Perregaard J, Lenz SM, Sanchez C, Falch E, Frølund B, Bolvig T, Sarup A, Larsson OM, Schousboe A, Krogsgaard-Larsen P (2005) Selective inhibitors of GABA uptake: Synthesis and molecular pharmacology of 4-N-methylamino-4,5,6,7-tetrahydrobenzo[d]isoxazol-3-ol analogues. Bioorg Med Chem 13:895-908

Conti P, Roda G, Stabile H, Vanoni MA, Curti B, De Amici M (2003) Synthesis and biological evaluation of new amino acids structurally related to the antitumoragent acivicin. Farmaco 58:683-690

Cronin MTD, Aptula AO, Dearden JC, Duffy JC, Netzeva TI, Patel H, Rowe PH, Schultz TW, Worth AP, Voutzoulidis K, Schüürmann G (2002) Structure-based classification of antibacterial activity. J Chem Inf Comput Sci 42:869-878

Crossley JA, Browne DL (2010) An alkynyliodide cycloaddition strategy for the construction of iodoisoxazoles. J Org Chem 75:5414-5416

Dallanoce C, Frigerio F, De Amici M, Dorsch S, Klotz K-N, De Micheli C (2007) Novel chiral isoxazole derivatives: Synthesis and pharmacological characterization at human $\beta$-adrenergic receptor subtypes. Bioorg Med Chem 15:2533-2543

Deng B-L, Zhao Y, Hartmanb TL, Watson K, Buckheit RW, Pannecouque C, Clercq EDe, Cushmana M (2009) Synthesis of alkenyldiarylmethanes (ADAMs) containing benzo[d]isoxazole and oxazolidin-2-one rings, a new series of potent non-nucleoside HIV-1 reverse transcriptase inhibitors. Eur J Med Chem 44:1210-1214

Denmark SE, Kallemeyn JM (2005) Synthesis of 3,4,5-trisubstituted isoxazoles via sequential $[3+2]$ cycloaddition/silicon-based cross-coupling reactions. J Org Chem 70:2839-2842

Desjardins CA, Cohen KA, Munsamy V, Abeel T, Maharaj K, Walker BJ, Shea TP, Almeida DV, Manson AL, Salazar A, Padayatchi N, O'Donnell MR, Mlisana KP, Wortman J, Birren BW, Grosset J, Earl AM, Pym AS (2016) Genomic and functional analyses of
Mycobacterium tuberculosis strains implicate ald in Dcycloserine resistance. Nat Genet 48:544-551

Diana P, Carbone A, Barraja P, Kelter G, Fiebig HH, Cirrincione G (2010) Synthesis and antitumor activity of 2,5-bis(3'-indolyl)furans and 3,5-bis(3'-indolyl)-isoxazoles, nortopsentin analogues. Bioorg Med Chem 18:4524-4529

Dou G, Xu P, Li Q, Xi Y, Huang Z, Shi D (2013) Clean and efficient synthesis of isoxazole derivatives in aqueous media. Molecules 18:13645-13653

Eddington ND, Cox DS, Roberts RR, Butcher RJ, Edafiogho IO, Stables JP, Cooke N, Goodwin AM, Smith CA, Scott KR (2002) Synthesis and anticonvulsant activity of enaminones. 4. Investigations on isoxazole derivatives. Eur J Med Chem 37:635-648

Elnagdi MH, Rifaat M, Elmoghayar H, Abdel E, Hafez A, Alnima HH (1975) Reaction of 2-Arylhydrazono-3-oxonitriles with Hydroxylamine. Synthesis of 3-Amino-4-arylazoisoxazoles. J Org Chem 40:2604-2607

Falch E, Perregaard J, Frølund B, Søkilde B, Buur A, Hansen LM, Frydenvang K, Brehm L, Bolvig T, Larsson OM, Sanchez C, White HS, Schousboe A, Krogsgaard-Larsen P (1999) Selective inhibitors of glial gaba uptake: synthesis, absolute stereochemistry, and pharmacology of the enantiomers of 3-hydroxy-4amino-4,5,6,7-tetrahydro-1,2-benzisoxazole (exo-THPO) and analogues. J Med Chem 42:5402-5414

Frølund B, Jensen LS, Storustovu SI, Stensbøl TB, Ebert B, Kehler J, Krogsgaard-Larsen P, Liljefors T (2007) 4-Aryl-5-(4-piperidyl)3-isoxazolol GABA A antagonists: synthesis, pharmacology, and structure-activity relationships. J Med Chem 50:1988-1992

Gautam KC, Singh DP (2013) Synthesis and antimicrobial activity of some isoxazole derivatives of thiophene. Chem Sci Trans 2:992-996

Gayon E, Quinonero O, Lemouzy S, Vrancken E, Campagne JM (2011) Transition-metal-catalyzed uninterrupted four-step sequence to access trisubstituted isoxazoles. Org Lett 13:6418-6421

Genc Y, Ozkanca R, Bekdemir Y (2008) An overview on some benzimidazole and sulfonamide derivatives with anti-microbial activity. Ann Clin Microbiol Antimicrob 7:17-25

Genin MJ, Bueno AB, Agejas Francisco J, Manninen PR, Bocchinfuso WP, Montrose-Rafizadeh C, Cannady EA, Jones TM, Stille JR, Raddad E, Reidy C, Cox A, Michael MD, Michael LF (2015) Discovery of 6-(4-\{[5-Cyclopropyl-3-(2,6-dichlorophenyl)isoxazol-4-yl]methoxy \}piperidin-1-yl)-1-methyl-1H -indole-3-carboxylic Acid: A Novel FXR Agonist for the treatment of dyslipidemia. J Med Chem 58:9768-9772

Giustina A, Malerba M, Bresciani E, Desenzani P, Licini M, Zaltieri G, Grassi V (1995) Effect of two beta 2-agonist drugs, salbutamol and broxaterol, on the growth hormone response to exercise in adult patients with asthmatic bronchitis. J Endocrinol Invest $18: 847-852$

Golicki D, Newada M, Lis J, Pol K, Hermanowski T, Tłustochowicz M (2012) Leflunomide in monotherapy of rheumatoid arthritis: meta-analysis of randomized trials. Pol Arch Med Wewn 122:22-32

Guo S, Wang J, Zhang X, Cojean S, Loiseau PM, Fan X (2015) Synthesis of 5-isoxazol-3-yl-pyrimidine nucleosides as potential antileishmanial agents. Bioorg Med Chem Lett 25:2617-2620

Gutiérrez M, Matus MF, Poblete T, Amigo J, Vallejos G, Astudillo L (2013) Isoxazoles: synthesis, evaluation and bioinformatic design as acetylcholinesterase inhibitors. J Pharm Pharmacol 65:1796-1804

Habeeb AG, Praveen Rao PN, Knaus EE (2001) Design and synthesis of 4,5-diphenyl-4-isoxazolines: Novel inhibitors of cyclooxygenase-2 with analgesic and antiinflammatory activity. $\mathbf{J}$ Med Chem 44:2921-2927 
Hansen TV, Wu P, Fokin VV (2005) One-Pot Copper(I)-Catalyzed Synthesis of 3,5-Disubstituted Isoxazoles. J Org Chem 70:7761-7764

Harigae R, Moriyama K, Togo H (2014) Preparation of 3,5-disubstituted pyrazoles and isoxazoles from terminal alkynes, aldehydes, hydrazines, and hydroxylamine. J Org Chem 79:2049-2058

He Y, Duckett D, Chen W, Ling YY, Cameron MD, Lin L, Ruiz CH, Lograsso PV, Kamenecka TM, Koenig M (2014) Synthesis and SAR of novel isoxazoles as potent c-jun N-terminal kinase (JNK) inhibitors. Bioorg Med Chem Lett 24:161-164

Hu F, Szostak M (2015) Recent developments in the synthesis and reactivity of isoxazoles: metal catalysis and beyond. Adv Synth Catal 357:2583-2614

Huang M, Suk D-H, Cho N-C, Bhattarai D, Kang SB, Kim Y, Pae AN, Rhim H, Keum G (2015) Synthesis and biological evaluation of isoxazoline derivatives as potent M1 muscarinic acetylcholine receptor agonists. Bioorg Med Chem Lett 25:1546-1551

Huang Z-B, Li L-L, Zhao Y-W, Wang H-Y, Shi D-Q (2014) An efficient synthesis of isoxazoles and pyrazoles under ultrasound irradiation. J Heterocycl Chem 51:E309-E313

Im D, Jung K, Yang S, Aman W, Hah JM (2015) Discovery of 4arylamido 3-methyl isoxazole derivatives as novel FMS kinase inhibitors. Eur J Med Chem 102:600-610

Jadhav RD, Kadam KS, Kandre S, Guha T, Reddy MMK, Brahma MK, Deshmukh NJ, Dixit A, Doshi L, Potdar N, Enose AA, Vishwakarma RA, Sivaramakrishnan H, Srinivasan S, Nemmani KVS, Gupte A, Gangopadhyay AK, Sharma R (2012) Synthesis and biological evaluation of isoxazole, oxazole, and oxadiazole containing heteroaryl analogs of biaryl ureas as DGAT1 inhibitors. Eur J Med Chem 54:324-342

Jadhav RD, Mistry HD, Motiwala H, Kadam KS, Kandre S, Gupte A, Gangopadhyay AK, Sharma R (2013) A facile one-pot synthesis of 3,5-disubstituted isoxazole derivatives using hydroxy (tosyloxy) iodobenzene. J Heterocycl Chem 50:774-780

Jeong Y, Kim B, Lee JK, Ryu J (2014) Direct synthesis of 4fluoroisoxazoles through gold-catalyzed cascade cyclization-fluorination of 2-alkynone O-methyl oximes. J Org Chem 79:6444-6455

Ji S, Hong WP, Ko SH, Lee K (2006) The dipolar route to naphtho [2,1-c] isoxazoles from the Baylis-Hillman adducts of 2alkynylbenzaldehydes. J Heterocycl Chem 43:799-801

Jiang X, Liu H, Song Z, Peng X, Ji Y, Yao Q, Geng M, Ai J, Zhang A (2015) Discovery and SAR study of c-Met kinase inhibitors bearing an 3-amino-benzo[d]isoxazole or 3-aminoindazole scaffold. Bioorg Med Chem 23:564-578

Jin C, Navarro Ha, Page K, Carroll FI (2008) Synthesis and monoamine transporter binding properties of 2beta-[3'-(substituted benzyl)isoxazol-5-yl]- and 2beta-[3'-methyl-4'-(substituted phenyl)isoxazol-5-yl]-3beta-(substituted phenyl)tropanes. Bioorg Med Chem 16:6682-6688

Joshi SD, Dixit SR, Kirankumar MN, Aminabhavi TM, Raju KVSN, Narayan R, Lherbet C, Yang KS (2016) Synthesis, antimycobacterial screening and ligand-based molecular docking studies on novel pyrrole derivatives bearing pyrazoline, isoxazole and phenyl thiourea moieties. Eur J Med Chem 107:133-152

Kachhadia VV, Patel MR, Joshi HS (2004) Synthesis of isoxazoles and cyanopyridines bearing benzo (b) thiophene nucleus as potential antitubercular and antimicrobial agents. J Sci Islam Repub Iran 15:47-51

Kafle B, Aher NG, Khadka D, Park H, Cho H (2011) Isoxazol-5(4H) one derivatives as PTP1B inhibitors showing an anti-obesity effect. Chem - Asian J 6:2073-2079

Kafle B, Cho H (2012) Isoxazolone derivatives as potent inhibitors of PTP1B. Bull Korean Chem Soc 33:275-277
Kalirajan R, Rafick MHM, Sankar S, Jubie S (2012) Docking studies, synthesis, characterization and evaluation of their antioxidant and cytotoxic activities of some novel isoxazole-substituted 9-anilinoacridine derivatives. Sci World J 2012:1-6

Kamal A, Bharathi EV, Reddy JS, Ramaiah MJ, Dastagiri D, Reddy MK, Viswanath A, Reddy TL, Shaik TB, Pushpavalli SNCVL, Bhadra MP (2011) Synthesis and biological evaluation of 3,5diaryl isoxazoline/isoxazole linked 2,3-dihydroquinazolinone hybrids as anticancer agents. Eur J Med Chem 46:691-703

Kamal A, Surendranadha Reddy J, Janaki Ramaiah M, Dastagiri D, Vijaya Bharathi E, Ameruddin Azhar M, Sultana F, Pushpavalli SNCVL, Pal-Bhadra M, Juvekar A (2010) Design, synthesis and biological evaluation of 3,5-diaryl-isoxazoline/isoxazole-pyrrolobenzodiazepine conjugates as potential anticancer agents. Eur J Med Chem 45:3924-3937

Karthikeyan K, Veenus Seelan T, Lalitha KG, Perumal PT (2009) Synthesis and antinociceptive activity of pyrazolyl isoxazolines and pyrazolyl isoxazoles. Bioorg Med Chem Lett 19:3370-3373

Kesornpun C, Aree T, Mahidol C, Ruchirawat S, Kittakoop P (2016) Corrigendum: water-assisted nitrile oxide cycloadditions: synthesis of isoxazoles and stereoselective syntheses of isoxazolines and 1,2,4-oxadiazoles. Angew Chem Int Ed 55:10548-10548

Kiyani H (2013) Synthesis of 4-arylmethylidene-3-methyl-isoxazol-5 $(4 \mathrm{H})$-ones via a three-component reaction in water catalyzed by sodium ascorbate. Org Chem Indian J 9:97-101

Kiyani H, Ghorbani F (2013a) Synthesis of arylmethylidene-isoxazole-5 $(4 \mathrm{H})$-ones in water catalyzed by sodium citrate. Heterocycl Lett 3:145-153

Kiyani H, Ghorbani F (2013b) Synthesis of arylmethylidene-isoxazol$5(4 \mathrm{H})$-ones via three-component reaction in water catalyzed by sodium tetraborate. Open J Org Chem 1:5-9

Kiyani H, Ghorbani F (2013c) Synthesis of 4-arylmethyleneisoxazole5-one derivatives via a one-pot three-component reaction in water catalyzed by sodium azide. Elixir Org Chem 58A:14948-14950

Kiyani H, Ghorbani F (2013d) Potassium phthalimide as efficient basic organocatalyst for the synthesis of 3A4-disubstituted isoxazol5a4Ha-ones in aqueous medium. J Saudi Chem Soc 21: S112-S119

Kiyani H, Ghorbani F (2013e) Sodium saccharin as a clean and efficient catalyst for the synthesis of 4-arylidene-3-methylisoxazol-5 $(4 \mathrm{H})$-ones via one-pot three-component reaction in aqueous medium. Heterocycl Lett 3:359-369

Kiyani H, Ghorbani F (2015) Boric acid-catalyzed multi-component reaction for efficient synthesis of $4 \mathrm{H}$-isoxazol-5-ones in aqueous medium. Res Chem Intermed 41:2653-2664

Kiyani H, Kanaani A, Ajloo D, Ghorbani F, Vakili M (2015) Nbromosuccinimide(NBS)-promoted, three-component synthesis of $\alpha, \beta$-unsaturated isoxazol-5(4H)-ones, and spectroscopic investigation and computational study of 3-methyl-4-(thiophen-2ylmethylene)isoxazol-5(4H)-one. Res Chem Intermed 41:7739-7773

Koufaki M, Fotopoulou T, Kapetanou M, Heropoulos GA, Gonos ES, Chondrogianni N (2014) Microwave-assisted synthesis of 3,5disubstituted isoxazoles and evaluation of their anti-ageing activity. Eur J Med Chem 83:508-515

Koufaki M, Tsatsaroni A, Alexi X, Guerrand H, Zerva S, Alexis MN (2011) Isoxazole substituted chromans against oxidative stressinduced neuronal damage. Bioorg Med Chem 19:4841-4850

Kumar A, Maurya RA, Sharma S, Ahmad P, Singh AB, Tamrakar AK, Srivastava AK (2009) Design and synthesis of 3,5-diarylisoxazole derivatives as novel class of anti-hyperglycemic and lipid lowering agents. Bioorg Med Chem 17:5285-5292

Kumar J, Chawla G, Akhtar M, Sahu K, Rathore V, Sahu S (2017) Design, synthesis and pharmacological evaluation of some novel derivatives of 1-\{[3-(furan-2-yl)-5-phenyl-4,5-dihydro-1,2-oxazol-4-yl]methyl \}-4-methyl piperazine. Arab J Chem 10:141-149 
Kumbhare RM, Kosurkar UB, Janaki Ramaiah M, Dadmal TL, Pushpavalli SNCVL, Pal-Bhadra M (2012) Synthesis and biological evaluation of novel triazoles and isoxazoles linked 2-phenyl benzothiazole as potential anticancer agents. Bioorg Med Chem Lett 22:5424-5427

Lainson JC, Daly SM, Triplett K, Johnston SA, Hall PR, Diehnelt CW (2017) Synthetic antibacterial peptide exhibits synergy with Oxacillin against MRSA. ACS Med Chem Lett 8:853-857

Lasri J, Mukhopadhyay S, Charmier MAJ (2008) Efficient regioselective synthesis of 4- and 5-substituted isoxazoles under thermal and microwave conditions. J Heterocycl Chem 45:1385-1389

Laufer SA, Margutti S, Fritz MD (2006) Substituted isoxazoles as potent inhibitors of p38 MAP kinase. ChemMedChem 1:197-207

Lavanya G, Mallikarjuna Reddy L, Padmavathi V, Padmaja A (2014) Synthesis and antimicrobial activity of (1,4-phenylene)bis(arylsulfonylpyrazoles and isoxazoles). Eur J Med Chem 73:187-194

Lee YS, Park SM, Kim BH (2009) Synthesis of 5-isoxazol-5-yl-2'deoxyuridines exhibiting antiviral activity against HSV and several RNA viruses. Bioorg Med Chem Lett 19:1126-1128

Lehtonen K, Summers LA, Carter GA (1972) Fungitoxicity of acid and alkali hydrolysis products of Drazoxolon and related arylhydrazonoisoxazolones. Pestic Sci 3:357-364

Li Y, Gao M, Liu B, Xu B (2017) Copper nitrate-mediated chemo- and regioselective annulation from two different alkynes: a direct route to isoxazoles. Org Chem Front 4:445-449

Liu F, Wang M, Teng X, Zhang P, Jiang L (2014) Synthesis and biological evaluation of novel 2-(substituted isoxazol-4-yl)-5arylamino-1,3,4-oxadiazoles. Res Chem Intermed 40:1575-1581

Liu J, Yu LF, Eaton JB, Caldarone B, Cavino K, Ruiz C, Terry M, Fedolak A, Wang D, Ghavami A, Lowe DA, Brunner D, Lukas RJ, Kozikowski AP (2011) Discovery of isoxazole analogues of sazetidine-A as selective $\alpha 4 \beta 2$-nicotinic acetylcholine receptor partial agonists for the treatment of depression. J Med Chem 54:7280-7288

Liu T, Dong X, Xue N, Wu R, He Q, Yang B, Hu Y (2009) Synthesis and biological evaluation of 3,4-diaryl-5-aminoisoxazole derivatives. Bioorg Med Chem 17:6279-6285

Machetti F, Cecchi L, Trogu E, De Sarlo F (2007) Isoxazoles and isoxazolines by 1,3-dipolar cycloaddition: base-catalysed condensation of primary nitro compounds with dipolarophiles. Eur J Org Chem 2007:4352-4359

Mahajan SS, Scian M, Sripathy S, Posakony J, Lao U, Loe TK, Leko V, Thalhofer A, Schuler AD, Bedalov A, Simon JA (2014) Development of pyrazolone and isoxazol-5-one cambinol analogues as sirtuin inhibitors. J Med Chem 57:3283-3294

Majewsky M, Wagner D, Delay M, Bräse S, Yargeau V, Horn H (2014) Antibacterial activity of sulfamethoxazole transformation products (TPs): general relevance for sulfonamide TPs modified at the para position. Chem Res Toxicol 27:1821-1828

Malik S, Ahuja P, Sahu K, Khan SA (2014) Design and synthesis of new of 3-(benzo[d]isoxazol-3-yl)-1-substituted pyrrolidine-2,5dione derivatives as anticonvulsants. Eur J Med Chem 84:42-50

Malik S, Khan SA (2014) Design and synthesis of (5-amino-1, 2, 4triazin-6-yl)(2-(benzo[d] isoxazol-3-yl) pyrrolidin-1-yl)methanone derivatives as sodium channel blocker and anticonvulsant agents. J Enzym Inhib Med Chem 29:505-516

Mani SSR, Iyyadurai R (2017) Cloxacillin induced agranulocytosis: a rare adverse event of a commonly used antibiotic. Int $\mathrm{J}$ Immunopathol Pharmacol 30:297-301

Manna K, Banik U, Ghosh PS, Das M (2014) A review on synthesis and pharmacological diversity of isoxazoles \& pyrazolines. Nirma Univ J Pharm Sci 1:37-49

Mao J, Yuan H, Wang Y, Wan B, Pak D, He R, Franzblau SG (2010) Synthesis and antituberculosis activity of novel mefloquineisoxazole carboxylic esters as prodrugs. Bioorg Med Chem Lett 20:1263-1268
Mares D, Romagnoli C, Tosi B, Benvegnù R, Bruni A, Vicentini CB (2002) Mannan changes induced by 3-methyl-5-aminoisoxazole4-thiocyanate, a new azole derivative, on Epidermophyton floccosum. Fungal Genet Biol 36:47-57

Martins MAP, Flores AFC, Bastos GP, Sinhorin A, Bonacorso HG, Zanatta N (2000) A convenient one-pot synthesis of 5-carboxyisoxazoles: Trichloromethyl group as a carboxyl group precursor. Tetrahedron Lett 41:293-297

Maurya R, Ahmad A, Gupta P, Chand K, Kumar M, Jayendra, Rawat P, Rasheed N, Palit G (2011) Synthesis of novel isoxazolines via 1,3-dipolar cycloaddition and evaluation of anti-stress activity. Med Chem Res 20:139-145

Mazimba O, Wale K, Loeto D, Kwape T (2014) Antioxidant and antimicrobial studies on fused-ring pyrazolones and isoxazolones. Bioorg Med Chem 22:6564-6569

McKinney AR, Cawley AT, Young EB, Kerwick CM, Cunnington K, Stewart RT, Ambrus JI, Willis AC, McLeod MD (2013) The metabolism of anabolic-androgenic steroids in the greyhound. Bioanalysis 5:769-781

Md Tohid SF, Ziedan NI, Stefanelli F, Fogli S, Westwell AD (2012) Synthesis and evaluation of indole-containing 3,5-diarylisoxazoles as potential pro-apoptotic antitumour agents. Eur J Med Chem 56:263-270

Meleddu R, Distinto S, Cirilli R, Alcaro S, Yanez M, Sanna ML, Corona A, Melis C, Bianco G, Matyus P, Cottiglia F, Maccioni E (2017) Through scaffold modification to 3,5-diaryl-4,5-dihydroisoxazoles: new potent and selective inhibitors of monoamine oxidase B. J Enzym Inhib Med Chem 32:264-270

Mohammed S, Vishwakarma RA, Bharate SB (2015) Metal-free DBU promoted regioselective synthesis of isoxazoles and isoxazolines. RSC Adv 5:3470-3473

Mokale SN, Nevase MC, Sakle NS, Dube PN, Shelke VR, Bhavale SA, Begum A (2014) Synthesis and in-vivo hypolipidemic activity of some novel substituted phenyl isoxazol phenoxy acetic acid derivatives. Bioorg Med Chem Lett 24:2155-2158

Naidu KM, Suresh A, Subbalakshmi J, Sriram D, Yogeeswari P, Raghavaiah P, Chandra Sekhar KVG (2014) Design, synthesis and antimycobacterial activity of various 3-(4-(substituted sulfonyl)piperazin-1-yl)benzo[d]isoxazole derivatives. Eur J Med Chem 87:71-78

Najafi Z, Mahdavi M, Safavi M, Saeedi M, Alinezhad H, Pordeli M, Kabudanian Ardestani S, Shafiee A, Foroumadi A, Akbarzadeh T (2015) Synthesis and in vitro cytotoxic activity of novel triazoleisoxazole derivatives. J Heterocycl Chem 52:1743-1747

Nenajdenko VG, Zakurdaev EP, Gololobov AM, Balenkova ES (2005) Synthesis of 5-substituted 4-aminoalkylpyrazol-3-ones (isoxazol-3-ones) from 3-acyllactams. Russ Chem Bull $54: 220-225$

Oakdale JS, Sit RK, Fokin VV (2014) Ruthenium-catalyzed cycloadditions of 1-haloalkynes with nitrile oxides and organic azides: synthesis of 4-haloisoxazoles and 5-halotriazoles. ChemA Eur J 20:11101-11110

Olesen PH, Swedberg MDB, Rimvall K (1998) 3-(5-Alkylamino-4isoxazolyl)-1,2,5,6-tetrahydropyridines: a novel class of central nicotinic receptor ligands. Bioorg Med Chem 6:1623-1629

Ostacolo C, Ambrosino P, Russo R, Lo Monte M, Soldovieri MV, Laneri S, Sacchi A, Vistoli G, Taglialatela M, Calignano A (2013) Isoxazole derivatives as potent transient receptor potential melastatin type 8 (TRPM8) agonists. Eur J Med Chem 69:659-669

Özkay Y, İncesu Z, Önder Nİ, Tunalı Y, Karaca H, Işıkdağ İ, Uçucu Ü (2013) Antimicrobial and anticancer effects of some 2-(substitutedsulfanyl)-N-(5-methyl-isoxazol-3-yl)acetamide derivatives. Med Chem Res 22:211-218

Padmaja A, Payani T, Reddy GD, Padmavathi V (2009) Synthesis, antimicrobial and antioxidant activities of substituted pyrazoles, 
isoxazoles, pyrimidine and thioxopyrimidine derivatives. Eur $\mathbf{J}$ Med Chem 44:4557-4566

Padmaja A, Rajasekhar C, Muralikrishna A, Padmavathi V (2011) Synthesis and antioxidant activity of oxazolyl/thiazolylsulfonylmethyl pyrazoles and isoxazoles. Eur $\mathrm{J}$ Med Chem 46:5034-5038

Palin R, Abernethy L, Ansari N, Cameron K, Clarkson T, Dempster M, Dunn D, Easson AM, Edwards D, MacLean J, Everett K, Feilden H, Ho KK, Kultgen S, Littlewood P, McArthur D, McGregor D, McLuskey H, Neagu I, Neale S, Nisbet LA, Ohlmeyer M, Pham Q, Ratcliffe P, Rong Y, Roughton A, Sammons M, Swanson R, Tracey H, Walker G (2011) Structure-activity studies of a novel series of isoxazole-3-carboxamide derivatives as TRPV1 antagonists. Bioorg Med Chem Lett 21:892-898

Panathur N, Gokhale N, Dalimba U, Koushik PV, Yogeeswari P, Sriram D (2015) New indole-isoxazolone derivatives: Synthesis, characterisation and in vitro SIRT1 inhibition studies. Bioorg Med Chem Lett 25:2768-2772

Panda S, Chowdary P, Jayashree B (2009) Synthesis, antiinflammatory and antibacterial activity of novel indolyl-isoxazoles. Indian $\mathbf{J}$ Pharm Sci 71:684-687

Patel D, Kumari P, Patel NB (2014) Synthesis and biological evaluation of coumarin based isoxazoles, pyrimidinthiones and pyrimidin-2-ones. Arab J Chem 10:S3990-S4001

Patil PO, Bari SB (2013) Synthesis and Antidepressant activity of some new 5-(1H-indol-3-yl)-3-(substituted aryl)-4,5-dihydroisoxazoline derivatives. J Chem 2013:1-8

Pedada SR, Yarla NS, Tambade PJ, Dhananjaya BL, Bishayee A, Arunasree KM, Philip GH, Dharmapuri G, Aliev G, Putta S, Rangaiah G (2016) Synthesis of new secretory phospholipase A2-inhibitory indole containing isoxazole derivatives as antiinflammatory and anticancer agents. Eur $\mathrm{J}$ Med Chem 112:289-297

Peifer C, Abadleh M, Bischof J, Hauser D, Schattel V, Hirner H, Knippschild U, Laufer S (2009) 3,4-Diaryl-isoxazoles and -imidazoles as potent dual inhibitors of $\mathrm{p} 38 \alpha$ mitogen activated protein kinase and casein kinase 18. J Med Chem 52:7618-7630

Peifer C, Wagner G, Laufer S (2006) New approaches to the treatment of inflammatory disorders small molecule inhibitors of p38 MAP kinase. Curr Top Med Chem 6:113-149

Peng-fei L, Ji-feng Z, Tao Y, Li-xia X, Zheng-ming LI (2012) Design, synthesis and insecticidal activities of novel phenyl substituted isoxazolecarboxamides. Chem Res Chin Univ 28:430-433

Pérez JM, Ramón DJ (2015) Synthesis of 3,5-disubstituted isoxazoles and isoxazolines in deep eutectic solvents. ACS Sustain. Chem Eng 3:2343-2349

Perrone MG, Vitale P, Panella A, Ferorelli S, Contino M, Lavecchia A, Scilimati A (2016) Isoxazole-based-scaffold inhibitors targeting cyclooxygenases (COXs). ChemMedChem 11:1172-1187

Rajanarendar E, Rama Krishna S, Nagaraju D, Govardhan Reddy K, Kishore B, Reddy YN (2015) Environmentally benign synthesis, molecular properties prediction and anti-inflammatory activity of novel isoxazolo[5,4-d]isoxazol-3-yl-aryl-methanones via vinylogous Henry nitroaldol adducts as synthons. Bioorg Med Chem Lett 25:1630-1634

Raji Reddy C, Vijaykumar J, Jithender E, Reddy GPK, Gree R (2012) One-pot synthesis of 3,5-disubstituted isoxazoles from propargylic alcohols through propargylic $\mathrm{N}$-hydroxylamines. Eur J Org Chem 2012:5767-5773

Rakesh SD, Lee RB, Tangallapally RP, Lee RE (2009) Synthesis, optimization and structure-activity relationships of 3,5-disubstituted isoxazolines as new anti-tuberculosis agents. Eur $\mathrm{J}$ Med Chem 44:460-472

RamaRao RJ, Rao AKSB, Sreenivas N, Kumar BS, Murthy YLN (2011) Synthesis and antibacterial activity of novel 5-(heteroaryl) isoxazole Derivatives. J Korean Chem Soc 55:243-250
Ratnakar Reddy K, Sambasiva Rao P, Jitender Dev G, Poornachandra Y, Ganesh Kumar C, Shanthan Rao P, Narsaiah B (2014) Synthesis of novel 1,2,3-triazole/isoxazole functionalized $2 \mathrm{H}$ Chromene derivatives and their cytotoxic activity. Bioorg Med Chem Lett 24:1661-1663

Sahu S, Banerjee M, Sahu D, Behera C, Pradhan G, Azam MA (2009) Synthesis, analgesic and antimicrobial activities of some novel isoxazole derivatives. Dhaka Univ J Pharm Sci 7:113-118

Samai S, Chanda T, Ila H, Singh MS (2013) One-Pot Three-component heteroannulation of $\beta$-oxo dithioesters, amines and hydroxylamine: regioselective, facile and straightforward entry to 5substituted 3-aminoisoxazoles. Eur J Org Chem 2013:4026-4031

Sambasiva Rao P, Kurumurthy C, Veeraswamy B, Poornachandra Y, Ganesh Kumar C, Narsaiah B (2014) Synthesis of novel 5-(3alkylquinolin-2-yl)-3-aryl isoxazole derivatives and their cytotoxic activity. Bioorg Med Chem Lett 24:1349-1351

Schoretsanitis G, Spina E, Hiemke C, de Leon J (2017) A systematic review and combined analysis of therapeutic drug monitoring studies for long-acting risperidone. Expert Rev Clin Pharmacol 10:965-981

Shader RI, Greenblatt DJ (1999) The reappearance of a monamine oxidase inhibitor (isocarboxazid). J Clin Psychopharmacol 19:105-106

Shailaja M, Manjula A, Rao BV, Praseeda B, Reddy BM (2011) Synthesis of novel 3, 5-disubstituted-4,5-dihydroisoxazoles and 3,4,5- trisubstituted isoxazoles and their biological activity. Indian J Chem - Sect B Org Med Chem 50:214-222

Shakeel-u-Rehman M-ur-R, Tripathi VK, Singh J, Ara T, Koul S, Farooq S, Kaul A (2014) Synthesis and biological evaluation of novel isoxazoles and triazoles linked 6-hydroxycoumarin as potent cytotoxic agents. Bioorg Med Chem Lett 24:4243-4246

Shaw J, Chen B, Bourgault JP, Jiang H, Kumar N, Mishra J, Valeriote FA, Media J, Bobbitt K, Pietraszkiewicz H, Edelstein M, Andreana PR (2012) Synthesis and biological evaluation of novel $\mathrm{N}$-phenyl-5-carboxamidyl isoxazoles as potential chemotherapeutic agents for colon cancer. Am J Biomed Sci 4:14-25

Sherin DR, Rajashekharan KN (2016) Curcuminoid-derived 3,5-bis (styryl)isoxazoles - mechanochemical synthesis and antioxidant activity. J Chem Sci 128:1315-1319

Shin JH, Gadde KM, Østbye T, Bray GA (2014) Weight changes in obese adults 6-months after discontinuation of double-blind zonisamide or placebo treatment. Diabetes Obes Metab $16: 766-768$

Siddiqui N, Idrees M, Khati NT, Dhonde MG (2013) Synthesis and antimicrobial activities of some new pyrazoles, oxadiazoles and isoxazole bearing benzofuran moiety. South Afr J Chem 66:248-253

Silva NM, Tributino JLM, Miranda ALP, Barreiro EJ, Fraga CAM (2002) New isoxazole derivatives designed as nicotinic acetylcholine receptor ligand candidates. Eur J Med Chem 37:163-170

Simoni D, Roberti M, Invidiata FP, Rondanin R, Baruchello R, Malagutti C, Mazzali A, Rossi M, Grimaudo S, Capone F, Dusonchet L, Meli M, Raimondi MV, Landino M, D'Alessandro N, Tolomeo M, Arindam D, Lu S, Benbrook DM (2001) Heterocycle-Containing Retinoids. Discovery of a novel isoxazole arotinoid possessing potent apoptotic activity in multidrug and drug-induced apoptosis-resistant cells. J Med Chem 44:2308-2318

Srinivas A, Nagaraj A, Reddy CS (2010) Synthesis and in vitro study of methylene-bis-tetrahydro[1,3]thiazolo[4,5-c]isoxazoles as potential nematicidal agents. Eur J Med Chem 45:2353-2358

Srinivas A, Nagaraj A, Sanjeeva Reddy C (2009) Synthesis and in vitro study of a new class of methylene-bis-4,6-diarylbenzo[d] isoxazoles as potential antifungal agents. J Heterocycl Chem $46: 497-502$ 
Sysak A, Obmińska-Mrukowicz B (2017) Isoxazole ring as a useful scaffold in a search for new therapeutic agents. Eur J Med Chem 137:292-309

Trogu E, Vinattieri C, De Sarlo F, Machetti F (2012) Acid-basecatalysed condensation reaction in water: Isoxazolines and isoxazoles from nitroacetates and dipolarophiles. Chem-A Eur J 18:2081-2093

Tzanetou E, Liekens S, Kasiotis KM, Melagraki G, Afantitis A, Fokialakis N, Haroutounian SA (2014) Antiproliferative novel isoxazoles: Modeling, virtual screening, synthesis, and bioactivity evaluation. Eur J Med Chem 81:139-149

Vaidya SD, Kumar BVS, Kumar RV, Bhise UN, Mashelkar UC (2007) Synthesis, anti-bacterial, anti-asthmatic and anti-diabetic activities of novel $\mathrm{N}$-substituted-2-(benzo[d]isoxazol-3-ylmethyl)-1H-benzimidazoles. J Heterocycl Chem 44:685-691

Valizadeh H, Amiri M, Gholipur H (2009) Efficient and convenient method for the synthesis of isoxazoles in ionic liquid. J Heterocycl Chem 46:108-110

Verma A, Wong DM, Islam R, Tong F, Ghavami M, Mutunga JM, Slebodnick C, Li J, Viayna E, Lam PC-H, Totrov MM, Bloomquist JR, Carlier PR (2015) 3-Oxoisoxazole-2(3H)-carboxamides and isoxazol-3-yl carbamates: Resistance-breaking acetylcholinesterase inhibitors targeting the malaria mosquito, Anopheles gambiae. Bioorg Med Chem 23:1321-1340

Vitale P, Perrone MG, Malerba P, Lavecchia A, Scilimati A (2014) Selective COX-1 inhibition as a target of theranostic novel diarylisoxazoles. Eur J Med Chem 74:606-618

Vitale P, Tacconelli S, Perrone MG, Malerba P, Simone L, Scilimati A, Lavecchia A, Dovizio M, Marcantoni E, Bruno A, Patrignani P (2013) Synthesis, pharmacological characterization, and docking analysis of a novel family of diarylisoxazoles as highly selective cyclooxygenase-1 (COX-1) inhibitors. J Med Chem 56:4277-4299

Wagner E, Al-Kadasi K, Zimecki M, Sawka-Dobrowolska W (2008) Synthesis and pharmacological screening of derivatives of isoxazolo[4,5-d]pyrimidine. Eur J Med Chem 43:2498-2504

Wagner E, Becan L, Nowakowska E (2004) Synthesis and pharmacological assessment of derivatives of isoxazolo[4,5-d]pyrimidine. Bioorg Med Chem 12:265-272

Wang K, Xiang D, Liu J, Pan W, Dong D (2008) Substituted 1H -pyrazoles and isoxazoles from cyclopropyl oximes. Synfacts 2008:0695-0695

Watterson SH, Guo J, Spergel SH, Langevine CM, Moquin RV, Shen DR, Yarde M, Cvijic ME, Banas D, Liu R, Suchard SJ, Gillooly K, Taylor T, Rex-Rabe S, Shuster DJ, McIntyre KW, Cornelius G, D'Arienzo C, Marino A, Balimane P, Warrack B, Salter-Cid L, McKinnon M, Barrish JC, Carter PH, Pitts WJ, Xie J, Dyckman AJ (2016) Potent and selective agonists of sphingosine 1phosphate 1 (S1P1): Discovery and SAR of a novel isoxazole based series. J Med Chem 59:2820-2840

Weidner-Wells MA, Werblood HM, Goldschmidt R, Bush K, Foleno BD, Hilliard JJ, Melton J, Wira E, Macielag MJ (2004) The synthesis and antimicrobial evaluation of a new series of isoxazolinyl oxazolidinones. Bioorg Med Chem Lett 14:3069-3072
Willy B, Rominger F, Müller T (2008) Novel microwave-assisted onepot synthesis of isoxazoles by a three-component couplingcycloaddition sequence. Synthesis 2008:293-303

Xu Y, Wang N-Y, Song X-J, Lei Q, Ye T-H, You X-Y, Zuo W-Q, Xia Y, Zhang L-D, Yu L-T (2015) Discovery of novel N-(5-(tertbutyl)isoxazol-3-yl)-N'-phenylurea analogs as potent FLT3 inhibitors and evaluation of their activity against acute myeloid leukemia in vitro and in vivo. Bioorg Med Chem 23:4333-4343

Yamamoto T, Fujita K, Asari S, Chiba A, Kataba Y, Ohsumi K, Ohmuta N, Iida Y, Ijichi C, Iwayama S, Fukuchi N, Shoji M (2007) Synthesis and evaluation of isoxazole derivatives as lysophosphatidic acid (LPA) antagonists. Bioorg Med Chem Lett 17:3736-3740

Yamuna E, Kumar RA, Zeller M, Rajendra Prasad KJ (2012) Synthesis, antimicrobial, antimycobacterial and structure-activity relationship of substituted pyrazolo-, isoxazolo-, pyrimido- and mercaptopyrimidocyclohepta[b]indoles. Eur J Med Chem 47:228-238

Yang H, Xu G, Pei Y (2017) Synthesis, preliminary structure-activity relationships and biological evaluation of pyridinyl-4,5-2H-isoxazole derivatives as potent antitumor agents. Chem Res Chin Univ 33:61-69

Ye N, Zhu Y, Chen H, Liu Z, Mei FC, Wild C, Chen H, Cheng X, Zhou J (2015) Structure-activity relationship studies of substituted 2-(isoxazol-3-yl)-2-oxo-N'-phenyl-acetohydrazonoyl cyanide analogues: identification of potent exchange proteins directly activated by cAMP (EPAC) antagonists. J Med Chem 58:6033-6047

Yu GJ, Iwamoto S, Robins LI, Fettinger JC, Sparks TC, Lorsbach BA, Kurth MJ (2009) 3-(Arylthiomethyl)isoxazole-4,5-dicarboxamides: chemoselective nucleophilic chemistry and insecticidal activity. J Agric Food Chem 57:7422-7426

Yu L-F, Tückmantel W, Eaton JB, Caldarone B, Fedolak A, Hanania T, Brunner D, Lukas RJ, Kozikowski AP (2012) Identification of novel $\alpha 4 \beta 2$-nicotinic acetylcholine receptor (nAChR) agonists based on an isoxazole ether scaffold that demonstrate antidepressant-like activity. J Med Chem 55:812-823

Zhang C, Wang X, Liu H, Zhang M, Geng M, Sun L, Shen A, Zhang A (2017) Design, synthesis and pharmacological evaluation of 4,5-diarylisoxazols bearing amino acid residues within the 3amido motif as potent heat shock protein 90 (Hsp90) inhibitors. Eur J Med Chem 125:315-326

Zhang HK, Eaton JB, Fedolak A, Gunosewoyo H, Onajole OK, Brunner D, Lukas RJ, Yu LF, Kozikowski AP (2016) Synthesis and biological evaluation of novel hybrids of highly potent and selective $\alpha 4 \beta 2$-Nicotinic acetylcholine receptor (nAChR) partial agonists. Eur J Med Chem 124:689-697

Zhao N, Zuo L, Li W, Guo W, Liu W, Wang J (2017a) Greenhouse and field evaluation of isoxaflutole for weed control in maize in China. Sci Rep 7:12690-12698

Zhao S, Zhang X, Wei P, Su X, Zhao L, Wu M, Hao C, Liu C, Zhao D, Cheng M (2017b) Design, synthesis and evaluation of aromatic heterocyclic derivatives as potent antifungal agents. Eur $\mathbf{J}$ Med Chem 137:96-107 